\title{
Toughened carbon fibre-reinforced polymer composites with nanoparticle-modified epoxy matrices
}

\author{
D. Carolan ${ }^{1,2, \star}$, A. Ivankovic ${ }^{2}$, A. J. Kinloch ${ }^{1}$, S. Sprenger ${ }^{3}$, and A. C. Taylor ${ }^{1}$ \\ ${ }^{1}$ Department of Mechanical Engineering, Imperial College London, London SW7 2AZ, UK \\ ${ }^{2}$ School of Mechanical and Materials Engineering, University College Dublin, Belfield, Dublin 4, Ireland \\ ${ }^{3}$ Evonik Nutrition \& Care GmbH, Charlottenburger Strasse 9, 21502 Geesthacht, Germany
}

Received: 10 June 2016

Accepted: 1 October 2016

Published online:

17 October 2016

(C) The Author(s) 2016. This article is published with open access at Springerlink.com

\begin{abstract}
In the current work, the microstructure and fracture performance of carbon fibre-reinforced polymer (CFRP) composites based upon matrices of an anhydride-cured epoxy resin (formulated with a reactive diluent), and containing silica nanoparticles and/or polysiloxane core-shell rubber (CSR) nanoparticles, were investigated. Double cantilever beam tests were performed in order to determine the interlaminar fracture energy of the CFRP composites, while the single-edge-notched bend specimen was employed to evaluate the fracture energy of the bulk polymers. The fracture energy of the bulk epoxy polymers increased from $173 \mathrm{~J} / \mathrm{m}^{2}$ for the unmodified polymer to a maximum of $1237 \mathrm{~J} /$ $\mathrm{m}^{2}$ with the addition of $16 \mathrm{wt} \%$ of CSR nanoparticles. The toughening mechanisms were identified as (a) localised plastic shear yielding and (b) cavitation of the CSR particles followed by plastic void growth of the matrix. The steady-state propagation value of the interlaminar fracture energy of the CFRP composites increased with increasing nanoparticle concentration, from $1246 \mathrm{~J} / \mathrm{m}^{2}$ for the unmodified epoxy matrix to a maximum of $1851 \mathrm{~J} / \mathrm{m}^{2}$ with $4 \mathrm{wt} \%$ of silica nanoparticles and $8 \mathrm{wt} \%$ of CSR nanoparticles. Crack growth in the CFRP composites was dominated by fibre-bridging toughening mechanisms. The efficiency of the transfer of toughness from the bulk polymers to the carbon fibre composites was considered. The measured fracture energy of both bulk and composite materials decreased at a test temperature of $-80{ }^{\circ} \mathrm{C}$, compared with room temperature, i.e. $20^{\circ} \mathrm{C}$. Nevertheless, the toughening effects of both the silica and CSR nanoparticles on the bulk epoxy polymers and the CFRP composites, compared with the unmodified epoxy polymers, were still evident even at the lower temperature. Indeed, the toughening effect of the silica nanoparticles was greater at $-80{ }^{\circ} \mathrm{C}$ than at room temperature.
\end{abstract}




\section{Introduction}

Epoxy polymers find uses as adhesives and as the reinforcing matrix in high performance fibre composite materials. The highly crosslinked epoxy thermoset polymer possesses good temperature resistance and low creep properties. However, the relatively high degree of crosslinking also means that such polymers are inherently brittle. This may greatly limit their structural utility as engineering materials. The toughness of epoxy polymers can be improved by a number of means, e.g. plasticisation of the polymer [1], creation of an inter-penetrating network (IPN) [2] and the introduction of a second, well-dispersed, minority phase of either soft rubbery particles [3-5] or rigid inorganic particles [6-8]. More recently, experimental details on toughening with other materials have also emerged, such as by the addition of block copolymers [9-11], graphene and derivative materials [12] and carbon nanotubes [13, 14].

Rubber particles are the most commonly used, and generally effective, modifiers for toughening epoxy polymers. Both phase-separating reactive liquid rubbers [4, 15] and preformed core-shell rubber (CSR) particles have been used [16-20]. The toughening mechanisms in both cases have been previously identified as a combination of (a) plastic shearbanding in the epoxy polymer, and (b) particle cavitation and subsequent plastic void growth of the epoxy polymer $[4,5,21,22]$. Both of these toughening mechanisms are initiated by the presence of a welldispersed second phase of rubber particles. The use of a phase-separating rubber is often preferred over preformed CSR particles, as the CSR particles can be prone to agglomeration. However, it is difficult to precisely control the final particle size of the phaseseparated rubber particles, as it is governed by the balance between the reaction rate of the phase-separation process and the crosslinking process of the epoxy resin. Additionally the glass transition temperature, $T_{\mathrm{g}}$, of the epoxy polymer can be significantly reduced if any of the added rubber does not phase-separate, thereby effectively plasticising the epoxy [23]. In contrast, the $T_{\mathrm{g}}$ of the epoxy polymer is unaffected by the presence of the preformed CSR particles [18]. However, while the addition of rubber particles to epoxy polymers may dramatically increase their toughness, it does result in a reduction in the Young's modulus and yield strength of the epoxy due to the relatively low modulus and strength of the rubber [19].

The incorporation of rigid inorganic nanoparticles has also been found to improve the fracture properties of relatively brittle polymers such as epoxies. These relatively high modulus and stiff particles also result in an increase in both the strength and modulus of the modified epoxy polymer. Particular effort has focused on the toughening effects of glass [24-27] and silica [28-30]. A number of toughening mechanisms have been reported in the literature including crack pinning [31] and crack-path deflection [32, 33] in the case of micron-sized glass beads. The toughening mechanisms in silica nanoparticle-modified epoxies were found $[8,23,34,35]$ to be similar to the mechanisms observed in rubber-toughened epoxies, namely localised plastic shear-band yielding was initiated by the stress concentration acting around the periphery of the silica-nanoparticle and plastic void growth occurred in the epoxy polymer around those silica nanoparticles that had debonded [34, 35]. However, it has been noted experimentally that not all of the silica nanoparticles debonded from the matrix to initiate such plastic void growth of the epoxy [35]. Consequently, silica nanoparticles are generally not as effective at toughening an epoxy polymer as rubber particles.

The present work investigates the effect of incorporating both silica nanoparticles and CSR nanoparticles on the mechanical and fracture properties of an anhydride-cured epoxy polymer. The mechanical and fracture properties are measured both in the bulk polymer and also, for the first time, when such modified epoxy polymers are used as the matrices for carbon fibre polymer (CFRP) reinforced composites. The properties at low temperatures are also measured and the transferability of toughness from the bulk polymers to the CFRP composites is discussed, with an emphasis on elucidating the toughening mechanisms.

\section{Materials and methods}

\section{Resins and nanomodifiers}

A standard diglycidylether of bis-phenol A (DGEBA) epoxy resin was used as the basis for all the materials investigated in the current work: 'LY556' from Huntsman, UK, with an epoxide equivalent weight 
(EEW) of $185 \mathrm{~g} /$ eq. An anhydride curing agent, accelerated methylhexahydrophthalic acid, (Albidur HE600) with an anhydride equivalent weight (AEW) of $169 \mathrm{~g}$ / eq from Evonik Hanse, Germany, was used. The base resin formulation was further altered by the replacement of $25 \mathrm{wt} \%$ of the DGEBA resin with a reactive diluent, (1,6-hexanediol diglycidylether, DER 734, EEW = $160 \mathrm{~g} / \mathrm{eq}$ ) from Dow Chemical Co., Germany. In these epoxy polymers, which contained reactive diluent, the stoichiometric ratios were adjusted to account for the presence of the reactive diluent. The primary role of the reactive diluent is to reduce the viscosity of the resin mixture to allow for easier materials processing. The silica nanoparticles were obtained predispersed at $40 \mathrm{wt} \%$ in DGEBA, (Nanopox F400, Evonik Hanse). The silica nanoparticles used in the current work have a mean diameter of $20 \mathrm{~nm}$. The CSR particles were also predispersed in DGEBA at $40 \mathrm{wt} \%$. The CSR particles consisted of a polysiloxane core with a glass transition temperature of approximately $-100{ }^{\circ} \mathrm{C}$. The shell of the particles consisted of a very thin skin of epoxy-functional molecules grafted onto the core [18, 36]. The CSR particles have a lognormal distribution with a mean particle diameter of $160 \mathrm{~nm}$ and a standard deviation of $\pm 80 \mathrm{~nm}$. The density of the silica nanoparticles was calculated as $1800 \mathrm{~kg} / \mathrm{m}^{3}$ while that of the CSR nanoparticles was $990 \mathrm{~kg} / \mathrm{m}^{3}$.

The DGEBA epoxy resin was mixed with the epoxy containing the silica nanoparticles and/or the epoxy containing the CSR particles and/or the reactive diluent. These constituents were thoroughly mixed and degassed in a vacuum oven at a temperature of $60^{\circ} \mathrm{C}$. A stoichiometric amount of the curing agent was then added, mixed and degassed. The resin mixture was then poured into a pre-heated picture frame steel mould coated with a release agent (Frekote 700-NC, Henkel, UK), to produce plates from which bulk specimen test samples could be machined. The plates were cured at $90{ }^{\circ} \mathrm{C}$ for $1 \mathrm{~h}$, followed by a $2 \mathrm{~h}$ post-cure at $160^{\circ} \mathrm{C}$.

\section{Composite laminates}

The carbon fibre-reinforced plastic (CFRP) composite laminates were manufactured using the nanoparticlemodified epoxy polymers described in "Resins and nanomodifiers" section as the matrix materials. Ten layers of biaxial textile fabric (Toray T700Sc 50C) provided by Saertex $\mathrm{GmbH}$, Germany, were laid up in a $\pm 45^{\circ}$ configuration on a flat vacuum-assisted resin-infusion tool which could be heated, and sealed using a vacuum bag. The carbon fibre mat was then infused over a period of $8 \mathrm{~min}$ and subsequently cured under vacuum for a further $7 \mathrm{~h}$ at $110{ }^{\circ} \mathrm{C}$. The cured laminate was then subjected to a post-cure at atmospheric pressure for $13 \mathrm{~h}$ at $120^{\circ} \mathrm{C}$ and $2 \mathrm{~h}$ at $160^{\circ} \mathrm{C}$. It should noted that although somewhat different cure cycles were needed to satisfactorily manufacture the bulk and the CFRP composite specimens, the glass transition temperature, $T_{g}$, of the epoxy polymer in all cases was not significantly different in the two types of specimens. Indeed, the $T_{\mathrm{g}}$ of the bulk polymer was measured via dynamic mechanical analysis and compared to that obtained for the epoxy matrix in the CFRP laminates. In all cases, the $T_{\mathrm{g}}$ was measured to be $127 \pm 1{ }^{\circ} \mathrm{C}$.

\section{Mechanical properties}

Tensile tests were conducted on both the unmodified and nano-modified epoxy polymers to determine the tensile modulus in accordance with ISO 527 [37]. Dumbbell specimens with a gauge length of $30 \mathrm{~mm}$ were machined directly from the cast plates, which were $3 \mathrm{~mm}$ in thickness. A displacement rate of $1 \mathrm{~mm} / \mathrm{min}$ was used, and the tests were carried out both at room temperature (nominally $20 \pm 2{ }^{\circ} \mathrm{C}$ ) and at $-80{ }^{\circ} \mathrm{C}$. The strain was measured directly on the test specimen using a clip-on extensometer. At least five replicate tests were conducted for each material and the elastic modulus was calculated.

Plane-strain compression (PSC) tests were performed on bulk samples at both 20 and $-80{ }^{\circ} \mathrm{C}$. The PSC test allows determination of the yield stress, $\sigma_{\mathrm{yc}}$ and the high-strain behaviour, i.e. the failure strain, $\gamma_{\mathrm{f}}$. The tests were conducted as described by Williams and Ford [38] using polished test specimens of size $40 \times 40 \times 3 \mathrm{~mm}^{3}$. The test specimens were loaded in compression between two $12 \mathrm{~mm}$ wide parallel dies at a constant crosshead displacement rate of $0.1 \mathrm{~mm} /$ min. Care was taken to ensure that the effect of loadloop compliance was corrected for. The true compressive stress, $\sigma_{\mathrm{c}}$, was calculated using:

$\sigma_{\mathrm{c}}=\left(\frac{\sqrt{3}}{2}\right) \sigma_{\mathrm{E}}$,

while the compressive true strain, $\gamma$, was calculated via:

$\gamma=\left(\frac{2}{\sqrt{3}}\right) \ln \left(\frac{t_{\mathrm{c}}}{t}\right)$ 
where $\sigma_{\mathrm{E}}$ is the engineering stress, $t_{\mathrm{c}}$ is the thickness of the compressed specimen and $t$ is the original specimen thickness. At $20^{\circ} \mathrm{C}$, two replicate tests were conducted for each material, while at $-80^{\circ} \mathrm{C}$, only one test was conducted due to the difficulties associated with testing at such a low temperature. Additionally, the ultimate failure of the samples at low temperature was not recorded, as the load required to fail the specimens exceeded the capacity of the available load cell.

\section{Mode-I bulk fracture energy: single-edge notch bend (SENB) tests}

Single-edge-notched bending (SENB) tests in threepoint bend configuration were conducted to determine the plane-strain fracture toughness, $K_{\mathrm{Ic}}$ (bulk), and fracture energy, $G_{\text {Ic }}$ (bulk), in accordance with ISO-13586 [39]. Test specimens of dimensions $60 \times 12 \times 6 \mathrm{~mm}^{3}$ were machined from the cast plates which were $6 \mathrm{~mm}$ in thickness. These specimens were pre-notched to a depth of $4 \mathrm{~mm}$ before subsequent tapping a sharp precrack to a depth of $\sim 6 \mathrm{~mm}$ using a liquid nitrogen chilled razor blade. The length of this precrack was determined post-mortem using a stereo-optical microscope. Testing was conducted in a screw-driven universal testing machine at a constant crosshead displacement rate of $1 \mathrm{~mm} /$ $\mathrm{min}$. The fracture toughness is calculated via:

$K_{\text {Ic }}($ bulk $)=\frac{P}{b w^{1 / 2}} f(\alpha)$,

where $P$ is the load at failure, $b$ and $w$ are the sample thickness and width respectively and $f(\alpha)$ is a fitting function [39]. The fracture energy, $G_{\text {Ic }}$ (bulk), was calculated using the relationship:

$G_{\mathrm{Ic}}($ bulk $)=\frac{K_{\mathrm{Ic}}(\text { bulk })^{2}}{E_{\mathrm{t}}}\left(1-v^{2}\right)$,

where $E_{\mathrm{t}}$ is the tensile modulus of the polymer determined from the tensile tests and $v$ is the Poisson's ratio, which was taken to be 0.35 [18]. At least eight replicate specimens were tested for each bulk formulation at the two test temperatures.

\section{Mode-I interlaminar fracture energy: double cantilever beam (DCB) tests}

Fracture toughness tests of the CFRP composites were conducted using DCB specimens in accordance with ISO-15024 [40]. Test specimens of $150 \times 20 \times 3 \mathrm{~mm}^{3}$ were machined from composite panels. A $12 \mu \mathrm{m}$ thick PTFE crack starter film of length $50 \mathrm{~mm}$ was used to ensure an appropriately sharp starter crack. The corrected beam theory (CBT) method was employed to calculate both the mode-I initiation interlaminar fracture energy, $G_{I c, \text { init, }}$ and the steady-state propagation fracture energy, $G_{\text {Ic,prop }}$ of the composites. The interlaminar fracture energy was calculated via:

$G_{\text {IC }[\text { init,prop }]}(\operatorname{comp})=\frac{3 P \delta}{2 b(a+|\Delta|)} \frac{F}{N}$,

where $P$ is the load, $\delta$ is the displacement, $a$ the crack length and $b$ is the width of the specimen. The terms $F$ and $N$ are correction factors for large displacements and the presence of the load blocks, respectively. Finally, the term $\Delta$ is the correction factor to account for the fact that the DCB beam is not perfectly builtin.

The tests were conducted at a constant crosshead displacement rate of $5 \mathrm{~mm} / \mathrm{min}$ using a screw-driven tensile testing machine. The loads and displacements were recorded, and the crack lengths monitored using a travelling microscope. At least five replicate specimens were tested for each formulation of composite matrix at the two test temperatures. An $R$ curve was observed from the measured data, i.e. the value of the interlaminar fracture energy increased as the crack steadily propagated through the CFRP DCB test: from value for the onset, or initiation, of crack growth until an upper limit, steady-state value of the interlaminar fracture energy for crack propagation was attained. Thus, an initiation value, $G_{\text {Ic,init }}$ (comp), for the onset of crack growth and a value for steadystate propagation, $G_{\text {Ic,prop }}$ (comp), could be defined, as described in ISO-15024 [40]. (The value of $G_{\text {Ic,init }}(\mathrm{comp})$ was taken at the onset of nonlinearity of the load versus displacement curve during the first initial loading step, as defined in ISO-15024 [40].)

\section{Imaging studies}

Atomic force microscopy (AFM) was conducted to identify the microstructure of the samples. Microscopically smooth samples were prepared using a PowerTome XL cryo-microtome. The samples were prepared in a liquid nitrogen bath at $-100{ }^{\circ} \mathrm{C}$ to prevent smearing of the rubber particles. The surfaces were then scanned in tapping mode using a 
silicon probe at a scan rate of $1 \mathrm{~Hz}$ using a Bruker Multimode AFM. Both height and phase images were obtained during each scan.

A field-emission gun scanning-electron microscope (FEG-SEM) was used to obtain high-resolution images of the fracture surfaces of both the SENB and DCB samples. An accelerating voltage of between 3 and $5 \mathrm{kV}$ was applied. The samples were sputter coated with a $5 \mathrm{~nm}$ layer of gold-palladium, prior to examination, to prevent charging of the material.

\section{Results and discussion}

\section{Particle dispersion}

Figure 1 presents typical atomic force microscopy (AFM) micrographs of the bulk polymer nanocomposites investigated. It is shown that there is a good dispersion of both the silica nanoparticles, Fig. 1a, and the CSR nanoparticles when used as the sole nano-modifying agent, see Fig. $1 \mathrm{~b}$. Moreover, a good mutual dispersion of both silica and CSR nanoparticles was observed when a hybrid polymer, i.e. containing both types of nanoparticles together, was considered, Fig. 1c.

\section{Tensile modulus}

The tensile moduli of the epoxy polymers modified with either silica nanoparticles or CSR particles tested at both 20 and $-80{ }^{\circ} \mathrm{C}$ are given in Fig. 2. It should be noted that the measured values of the moduli do not differ significantly for the two test temperatures. A tensile modulus of $2.93 \pm 0.12 \mathrm{GPa}$ was measured for the unmodified epoxy polymer at $20^{\circ} \mathrm{C}$, while at $-80^{\circ} \mathrm{C}$, the tensile modulus was determined to be $3.04 \pm 0.02 \mathrm{GPa}$. In all cases, the modulus decreased approximately linearly with increasing CSR content, while an increase was observed with increasing silica nanoparticle content.

\section{Compressive properties}

The mean room temperature values of the true compressive yield stress, $\sigma_{\mathrm{yc}}$, true compressive failure stress, $\sigma_{\mathrm{fc}}$, and true compressive failure strain, $\gamma_{\mathrm{f}}$, are given in Table 1. The addition of CSR particles reduces the value of the compressive yield stress. This is expected due to the softness of the polysiloxane rubber compared with the epoxy polymer. However, the compressive yield stress of the epoxy polymer was unaffected by the addition of silica nanoparticles. This behaviour is unusual as the addition of a hard nanoparticle would typically result in an increase in the measured yield stress. However, a similar behaviour has been reported by both Liang and Pearson [34] and Zhang et al. [41], and this behaviour has previously been suggested by the current authors [36] to be due to the formation of a relatively soft interphase region around the silica nanoparticles. The addition of CSR particles to the epoxy polymers tended to suppress the amount of strain-softening post-yield, while the addition of silica nanoparticles was not observed to significantly affect the post-yield strain-softening behaviour. Huang and Kinloch [21, 22] have explained that the presence of the CSR particles suppresses the formation of macroscopic shear bands by promoting localised plastic shear-banding between the particles. These localised shear bands then merge to give a diffuse deformation zone and no macroscopic strain softening is observed in the stress-strain curve.

At the lower test temperature of $-80^{\circ} \mathrm{C}$, the epoxy polymers became much more difficult to deform plastically. The compressive yield stress increased from $94 \mathrm{MPa}$ at $20^{\circ} \mathrm{C}$ to $164 \mathrm{MPa}$ for the epoxy polymers tested at the lower temperature of $-80^{\circ} \mathrm{C}$. At this lower test temperature, there is no longer a well-defined upper yield point or a post-yield strainsoftening zone. Plots of representative true stress versus true strain curves of the unmodified epoxy polymer at the two test temperatures are given in Fig. 3. It should be noted that the $20{ }^{\circ} \mathrm{C}$ tests were conducted until ultimate failure of the materials, while the $-80{ }^{\circ} \mathrm{C}$ tests were conducted up to the load limit of the test machine. The loss of a distinct strainsoftening region at the lower test temperature can be clearly observed. While the current work was unable to determine the failure strain of the materials at $-80{ }^{\circ} \mathrm{C}$, work on a similar epoxy polymer by Chen et al. [18] reported a slight increase, of approximately $15-20 \%$, in the measured failure strain at such relatively low test temperatures.

A number of phenomenological and semi-empirical models have been proposed to predict the strength of particle-reinforced composites as reviewed in an excellent paper by Fu et al. [42]. This review concentrated on models where all, or almost all, of the parameters involved could be 


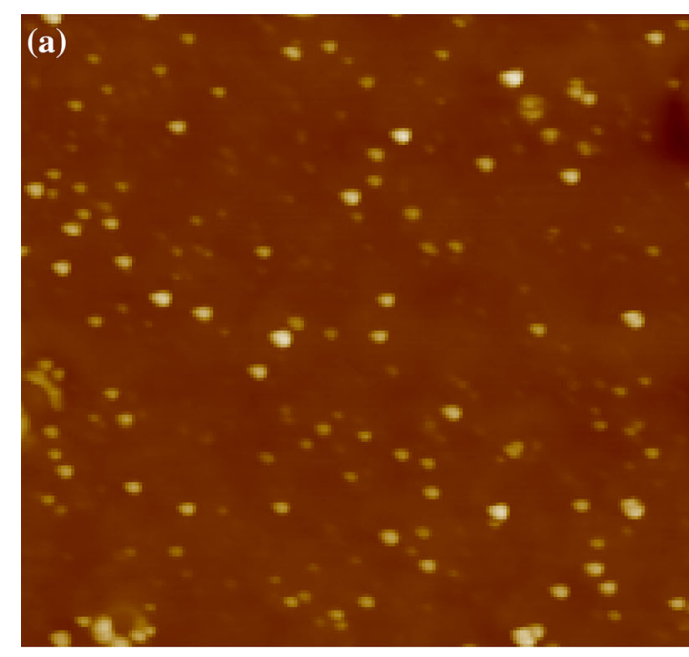

$400 \mathrm{~nm}$
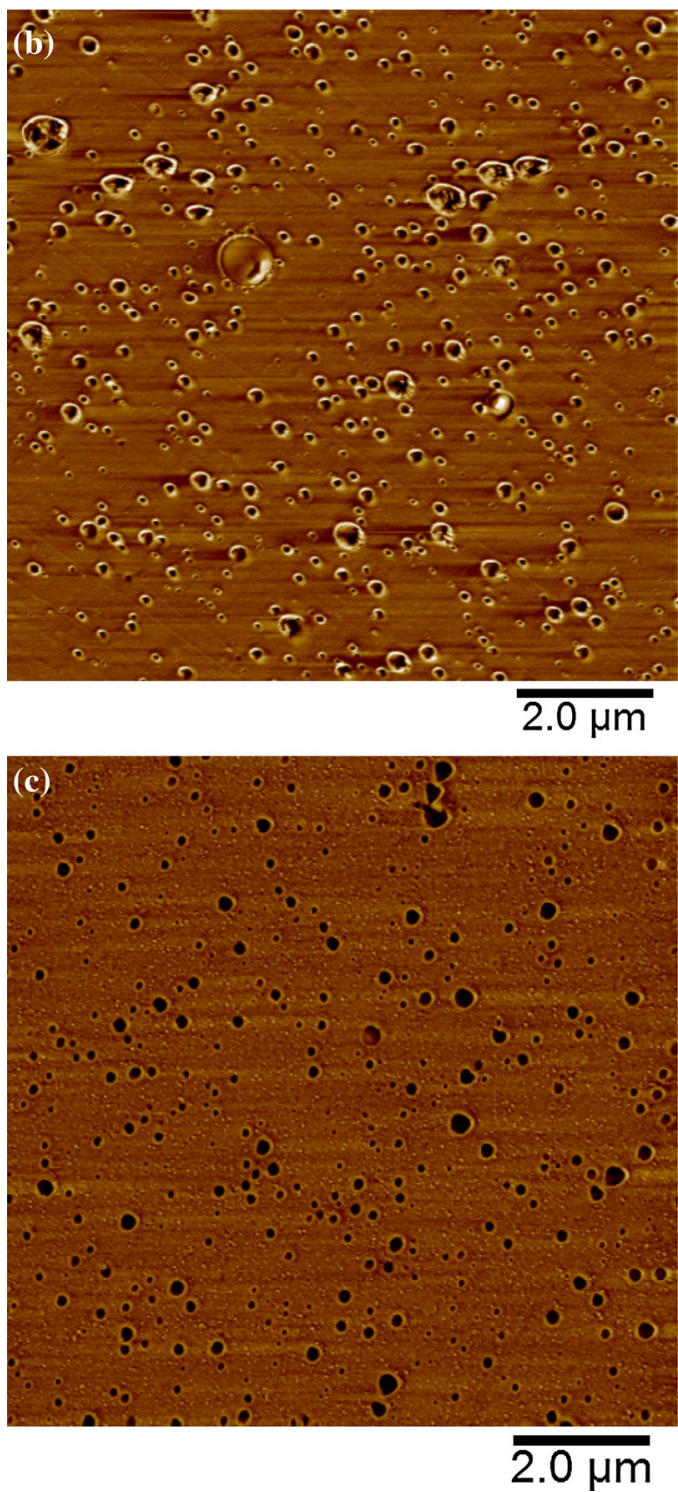

\Figure 1 a $4 \mathrm{wt} \%$ silica, $0 \mathrm{wt} \%$ CSR. b $0 \mathrm{wt} \%$ silica, $8 \mathrm{wt} \% \mathrm{CSR}$. c $8 \mathrm{wt} \%$ silica, $8 \mathrm{wt} \%$ CSR. AFM images of the microstructure of the bulk epoxy polymers modified with silica and CSR nanoparticles. The silica nanoparticles are indicated as the small yellow spots, while the CSR nanoparticles can be observed as much larger darkened circles.

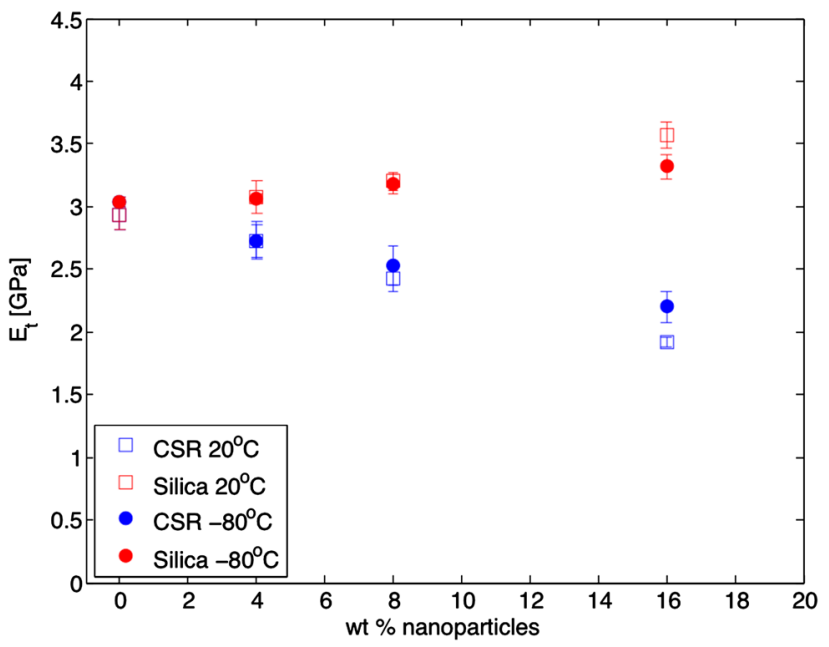

Figure 2 Experimentally measured tensile modulus, $E_{\mathrm{t}}$, of the bulk epoxy polymers at $20{ }^{\circ} \mathrm{C}$ and at $-80{ }^{\circ} \mathrm{C}$.

Table 1 Experimentally determined plane-strain compression properties of the bulk epoxy polymers

\begin{tabular}{lllll}
\hline Silica $(w t \%)$ & CSR $(w t \%)$ & $20{ }^{\circ} \mathrm{C}$ & \\
\cline { 3 - 5 } & & $\sigma_{\text {yc }}(\mathrm{MPa})$ & $\sigma_{\mathrm{fc}}(\mathrm{MPa})$ & $\gamma_{\mathrm{f}}$ \\
\hline 0 & 0 & $94 \pm 2$ & 169 & 0.89 \\
0 & 4 & $83 \pm 1$ & 175 & 0.86 \\
0 & 8 & $74 \pm 1$ & 171 & 1.00 \\
4 & 0 & $94 \pm 1$ & 210 & 0.94 \\
8 & 0 & $94 \pm 1$ & 242 & 0.91 \\
4 & 4 & $82 \pm 1$ & 193 & 0.95 \\
4 & 8 & $74 \pm 1$ & 166 & 0.89 \\
8 & 4 & $81 \pm 1$ & 205 & 0.86 \\
8 & 8 & $73 \pm 1$ & 195 & 0.92 \\
\hline
\end{tabular}

experimentally determined. However, these models for predicting the strength have not been as successful as those proposed to predict the value of the modulus [36]. Indeed, many of the strength-prediction models predict only a reduction in the yield strength of the composite with the addition of particles. In the case of a thermoset polymer modified with rubber particles, a weakening effect is always 


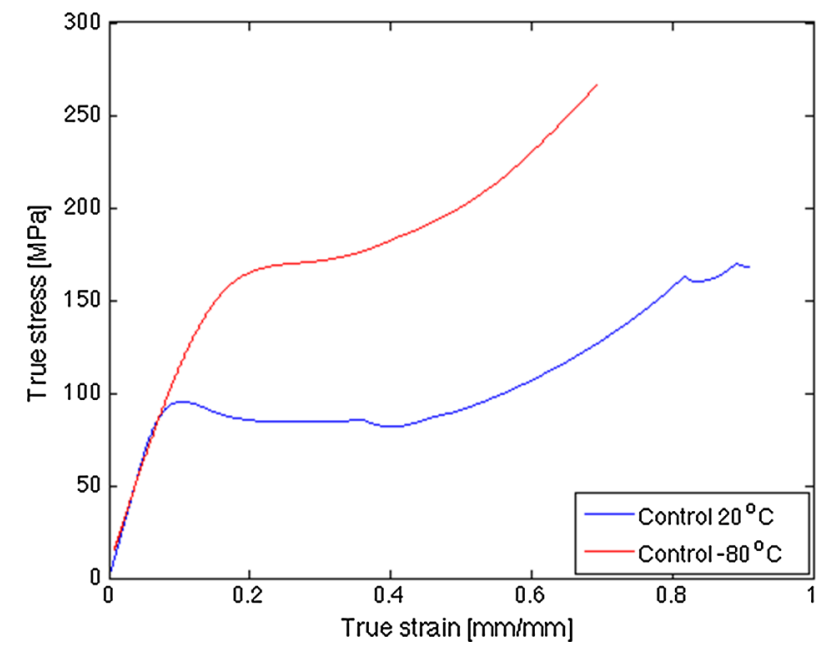

Figure 3 Experimentally measured true stress versus true strain curves from the plane-strain compression test for the unmodified bulk epoxy polymer. (Note The $20{ }^{\circ} \mathrm{C}$ test was conducted until ultimate failure of the material, while the $-80{ }^{\circ} \mathrm{C}$ test was conducted up to the load limit of the test machine.).

observed as the rubber particles are more compliant and weaker than the thermoset matrix, and therefore contribute less to the load-carrying capacity of the composite as well as providing a stress concentration due to the elastic mismatch between the particle and the surrounding epoxy polymer. For polymers modified with hard particles, the increased stiffness of the particles means that they make a greater contribution to the load-carrying capacity of the particlereinforced composite, thus reinforcing the composite. However, the stress concentration effect due to the presence of the particles still serves to weaken the material. Thus, the efficiency of stress transfer between the particles and the polymer becomes important to determine the dominant effect of the particles on the properties of the composite. Pukanszky et al. [43, 44] have proposed a semi-empirical relationship for predicting the strength of composite materials, which purports to take into account the interfacial bonding between the nanoparticles and the polymer:

$\sigma_{\mathrm{c}}=\left[\frac{1-v_{\mathrm{p}}}{1+2.5 v_{\mathrm{p}}}\right] e^{\beta v_{\mathrm{p}}}$,

where $\sigma_{\mathrm{c}}$ and $\sigma_{\mathrm{m}}$ are the strength of the modified and unmodified polymer respectively, $v_{p}$ is the volume fraction of particles and $\beta$ is an empirical constant related to the level of interfacial bonding between the particles and the polymer. Note that Eq. 6 can be used to predict the yield strength by replacing $\sigma_{\mathrm{c}}$ and

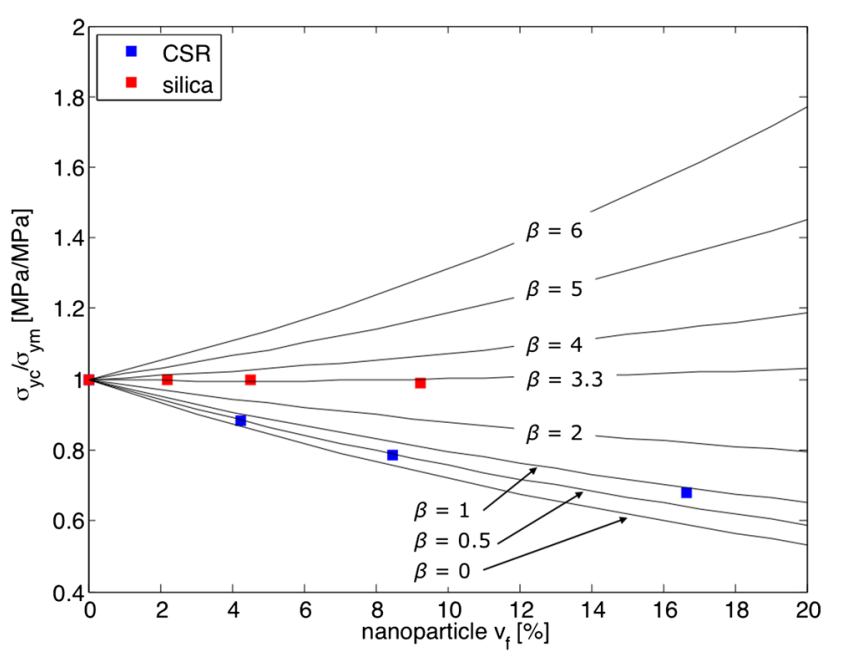

Figure 4 Variation of the normalised yield stress of the nanoparticle-modified bulk epoxy polymers tested at $20{ }^{\circ} \mathrm{C}$. The analytical solution for Eq. 6 is plotted for a number of different values of $\beta$.

$\sigma_{\mathrm{m}}$ with $\sigma_{\mathrm{yc}}$ and $\sigma_{\mathrm{ym}}$. Figure 4 plots the normalised particulate composite yield strength, $\sigma_{\mathrm{yc}} / \sigma_{\mathrm{ym}}$, at room temperature as a function of the volume fraction, $v_{f}$, of particles for various values of the empirical parameter $\beta$. For poor interfacial bonding, the particles do not carry any load, so $\beta=0$ and the filler particles act as voids. It can be seen that as the value of $\beta$ increases, so does the yield strength of the particle-reinforced material. More particularly, for values of $\beta<3.3$ the particle-polymer interaction is weak and no reinforcing effect is observed with the addition of particles, while for values of $\beta>3.3$, the yield strength is improved compared with the unmodified polymer. It should be noted that a direct comparison of the level of interfacial bonding between the CSR and silica nanoparticles cannot be made. This is because the value of the empirical parameter $\beta$ is not decoupled from the elastic properties of the particles, and hence the low value of $\beta$ measured for the CSR-modified epoxies is a reflection of the relative softness of those particles compared with the epoxy polymer. While the value of the empirical parameter $\beta$ gives a comparative indication of the level of bonding between the particle and the polymer, and is a useful tool to ascertain whether a specific surface treatment of the particle is effective at increasing or decreasing the interfacial bond, it does not provide any insight as to the nature of that adhesion nor any quantification of that adhesion.

Finally, a detailed interrogation of Table 1 shows that the yield strength of the hybrid epoxy polymers, 
i.e. those modified with both silica and CSR nanoparticles, is dominated by the behaviour of the rubber particles. This is expected as the strength of a composite is determined by the weakest link within a microstructure rather than a statistically averaged value over the microstructure, as is the case with the modulus properties.

\section{Fracture properties}

\section{The bulk epoxy polymers}

The mean values of the fracture energy, $G_{\mathrm{Ic}}$ (bulk), for the unmodified and modified bulk epoxy polymers that were measured at both 20 and $-80{ }^{\circ} \mathrm{C}$ are summarised in Table 2. The standard deviations are also given.

At room temperature, the fracture energy of the unmodified bulk epoxy polymer was $173 \pm 33 \mathrm{~J} / \mathrm{m}^{2}$. This increased to a value of $1237 \mathrm{~J} / \mathrm{m}^{2}$ with the addition of $16 \mathrm{wt} \%$ of CSR nanoparticles to the bulk epoxy polymer. The measured fracture energy increased steadily with increasing CSR content. The measured fracture energy of the unmodified epoxy polymer drops slightly at the lower test temperature of $-80{ }^{\circ} \mathrm{C}$, compared with the value at $20{ }^{\circ} \mathrm{C}$. Nevertheless, it can be seen that the addition of solely CSR nanoparticles can still significantly toughen the epoxy polymer at $-80{ }^{\circ} \mathrm{C}$, although the toughening increase observed is very much reduced when compared with the corresponding $20^{\circ} \mathrm{C}$ values. For example, a fracture energy of $469 \pm 60 \mathrm{~J} / \mathrm{m}^{2}$ was measured at $-80{ }^{\circ} \mathrm{C}$ for the epoxy polymer modified with 16 wt $\%$ of CSR nanoparticles, while a value of $1237 \pm 118 \mathrm{~J} / \mathrm{m}^{2}$ was measured at $20^{\circ} \mathrm{C}$ for the same formulation. However, for the $-80{ }^{\circ} \mathrm{C}$ tests this still represents a threefold increase in toughness compared with the unmodified epoxy polymer, demonstrating that the incorporation of these CSR nanoparticles is an effective means of toughening brittle epoxy polymers even at relatively low temperatures. The reduced toughness at $-80{ }^{\circ} \mathrm{C}$ for the epoxy polymers modified with CSR nanoparticles is primarily due to the increase in the yield stress of the epoxy. However, the stiffness of the polysiloxane CSR nanoparticles increases at low temperatures, thus increasing the cavitational resistance of the particles. While rubber elasticity predicts an increase in elastic modulus due to entropic effects, it is important to note that this is only true for temperatures significantly above the crystallisation temperature [45]. Rey et al. [45] have pointed out that this is approximately $-60{ }^{\circ} \mathrm{C}$ for the polysiloxane found in the CSR particles in the current work. This increase in the cavitational resistance of the particles limits the dissipation of energy via the plastic void growth mechanism, although computational studies by Guild et al. [46] have demonstrated that rubber particles cavitating at higher strains cause a far more complex shear-band dissipation mechanism and this can offset the loss of effectiveness of the void growth mechanisms. Finally, the increased resistance to plastic deformation of the matrix at the lower temperature limits the dissipation of energy via plastic deformation of the epoxy polymer.

Table 2 Measured fracture properties of the bulk epoxy polymers and CFRP composites

\begin{tabular}{|c|c|c|c|c|c|c|c|}
\hline \multirow{2}{*}{$\begin{array}{l}\text { Silica } \\
(w t \%)\end{array}$} & \multirow{2}{*}{$\begin{array}{l}\text { CSR } \\
(w t \%)\end{array}$} & \multicolumn{3}{|l|}{$20^{\circ} \mathrm{C}$} & \multicolumn{3}{|l|}{$-80^{\circ} \mathrm{C}$} \\
\hline & & $\begin{array}{l}\mathrm{G}_{\mathrm{Ic}}(\mathrm{bulk})(\mathrm{J} / \\
\left.\mathrm{m}^{2}\right)\end{array}$ & $\begin{array}{l}\mathrm{G}_{\mathrm{Ic}, \text { init }}(\mathrm{comp})(\mathrm{J} / \\
\left.\mathrm{m}^{2}\right)\end{array}$ & $\begin{array}{l}G_{\text {Ic,prop }}(\operatorname{comp})(\mathrm{J} / \\
\left.\mathrm{m}^{2}\right)\end{array}$ & $\begin{array}{l}\mathrm{G}_{\mathrm{Ic}}(\text { bulk })(\mathrm{J} / \\
\left.\mathrm{m}^{2}\right)\end{array}$ & $\begin{array}{l}G_{\text {Ic,init }}(\operatorname{comp})(\mathrm{J} / \\
\left.\mathrm{m}^{2}\right)\end{array}$ & $\begin{array}{l}G_{\text {Ic,prop }}(\text { comp })(\mathrm{J} / \\
\left.\mathrm{m}^{2}\right)\end{array}$ \\
\hline 0 & 0 & $173 \pm 33$ & $189 \pm 30$ & $1246 \pm 81$ & $149 \pm 33$ & $181 \pm 26$ & $867 \pm 68$ \\
\hline 0 & 4 & $507 \pm 101$ & $482 \pm 28$ & $1538 \pm 100$ & $329 \pm 53$ & $295 \pm 21$ & $1192 \pm 117$ \\
\hline 0 & 8 & $931 \pm 53$ & $753 \pm 99$ & $1680 \pm 129$ & $447 \pm 87$ & $479 \pm 18$ & $1095 \pm 172$ \\
\hline 0 & 16 & $1237 \pm 118$ & - & - & $469 \pm 60$ & - & - \\
\hline 4 & 0 & $188 \pm 24$ & $189 \pm 13$ & $1170 \pm 97$ & $246 \pm 26$ & $225 \pm 37$ & $1182 \pm 132$ \\
\hline 8 & 0 & $200 \pm 20$ & $217 \pm 16$ & $1311 \pm 118$ & $259 \pm 24$ & $265 \pm 39$ & $1072 \pm 111$ \\
\hline 16 & 0 & $257 \pm 42$ & - & - & $342 \pm 74$ & - & - \\
\hline 4 & 4 & $628 \pm 77$ & $380 \pm 60$ & $1624 \pm 139$ & $377 \pm 32$ & $332 \pm 22$ & $1188 \pm 214$ \\
\hline 4 & 8 & $1056 \pm 87$ & $547 \pm 43$ & $1851 \pm 78$ & $546 \pm 57$ & $348 \pm 32$ & $1184 \pm 78$ \\
\hline 8 & 4 & $724 \pm 109$ & $385 \pm 32$ & $1523 \pm 101$ & $404 \pm 23$ & $398 \pm 28$ & $1091 \pm 106$ \\
\hline 8 & 8 & $1217 \pm 63$ & $560 \pm 70$ & $1761 \pm 110$ & $563 \pm 57$ & $593 \pm 31$ & $1352 \pm 114$ \\
\hline
\end{tabular}


The toughening effect of adding solely silica nanoparticles at a test temperature of $20^{\circ} \mathrm{C}$ is much more limited, compared with adding CSR nanoparticles. The addition of $16 \mathrm{wt} \%$ of silica nanoparticles to the unmodified epoxy polymer only resulted in a marginal increase in the measured fracture energy, from $173 \pm 33$ to $257 \pm 42 \mathrm{~J} / \mathrm{m}^{2}$. It has been demonstrated previously that, for these formulations of bulk epoxy polymers, this relatively small increase is caused by a suppression of the typical toughening mechanisms of localised plastic shear-band yielding and plastic void growth of the epoxy polymer following debonding of the silica nanoparticles [36]. This has been suggested to be due to the presence of the reactive diluent in the epoxy resin formulation in the present work, which was shown to have the ability to form a soft interphase region around the silica nanoparticles [36]. It is very noteworthy that the toughening effect of the silica nanoparticles appears to be enhanced at the lower test temperature. For example, at $-80{ }^{\circ} \mathrm{C}$, a fracture energy of $342 \pm 74 \mathrm{~J} /$ $\mathrm{m}^{2}$ was measured for the epoxy polymer containing $16 \mathrm{wt} \%$ of silica nanoparticles, which is some $85 \mathrm{~J} / \mathrm{m}^{2}$ greater than the fracture energy of the corresponding formulation measured at $20{ }^{\circ} \mathrm{C}$. It seems likely that the toughening mechanisms suppressed at $20^{\circ} \mathrm{C}$ are reactivated at $-80^{\circ} \mathrm{C}$, as is discussed in detail below.

The subsequent addition of silica nanoparticles to epoxy polymers already containing CSR nanoparticles (i.e. to form a 'hybrid' epoxy polymer) produced only modest increases in the measured fracture energies at 20 and $-80{ }^{\circ} \mathrm{C}$, compared with the addition of solely the CSR nanoparticles. Nevertheless, from the results shown in Table 2, and as discussed in detail in [36], some synergistic effects can still be noted at $20^{\circ} \mathrm{C}$.

To further investigate the effect of test temperature on the bulk epoxy polymers, it is instructive to plot the measured fracture energies at the two test temperatures against each other. This is shown in Fig. 5. A number of points arise from a detailed inspection of these results. Firstly, the ratio of $G_{\mathrm{Ic}, \mathrm{LT}}$ (bulk)/ $G_{\mathrm{Ic}, \mathrm{RT}}$ (bulk) at the relatively low temperature (LT) compared to room temperature (RT) for all the epoxy polymers containing CSR nanoparticles reduces as the value of the measured fracture energy increases. Secondly, the effectiveness of toughening solely from the addition of silica nanoparticles gives a greater than unity value for the ratio of $G_{\mathrm{Ic}, \mathrm{LT}}$ (bulk) $/ G_{\mathrm{Ic}, \mathrm{RT}}$ (bulk), and this ratio is statistically independent of

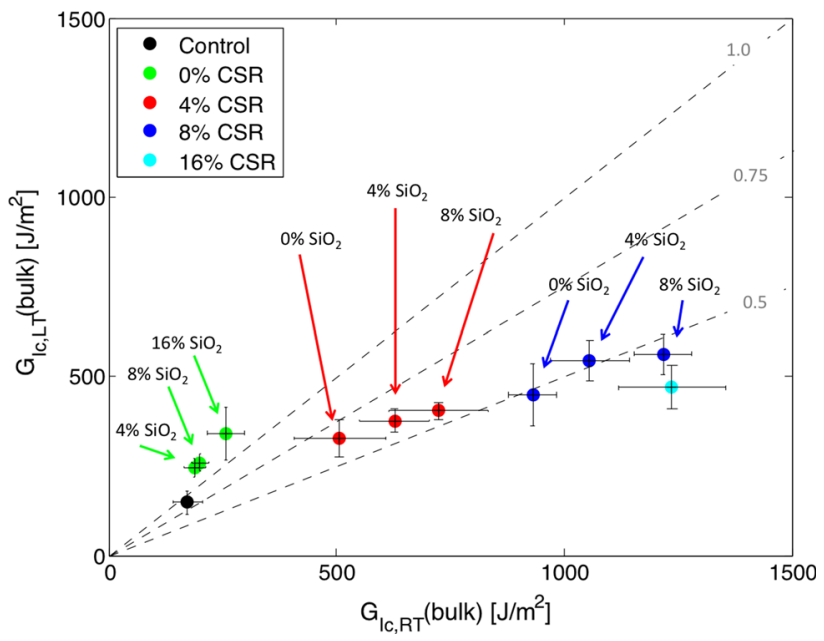

Figure 5 Comparison of measured fracture energies of the bulk epoxy polymers at -80 and $20{ }^{\circ} \mathrm{C}$. (The dashed lines have decreasing slopes of $1.0,0.75,0.5$, respectively to aid interpretation of the data.).

the concentration of the silica nanoparticles up to 16 wt $\%$. Finally, the effects of adding silica nanoparticles to an epoxy polymer already containing CSR nanoparticles, to form the hybrid-modified material, can be readily observed. The hybrid-modified bulk epoxy polymers are considerably tougher at $20^{\circ} \mathrm{C}$ than the corresponding polymers modified solely with CSR nanoparticles, while the effects on the toughness due to hybridisation of the CSR-modified polymers at $-80{ }^{\circ} \mathrm{C}$ are relatively small. Indeed, the ratio $G_{\mathrm{Ic}, \mathrm{LT}}$ (bulk)/ $G_{\mathrm{IC}, \mathrm{RT}}$ (bulk) for the hybrid-modified epoxy polymers is less than unity, being about 0.5 ; and the value of this ratio appears to be governed by the presence of the CSR nanoparticles rather than by the silica nanoparticles.

\section{Fractographic studies: bulk polymers}

The fracture surface of the unmodified bulk epoxy polymer appeared smooth and glassy, with river lines consisting of a series of steps generally aligned in the direction of crack propagation evident from the crack initiation point [47]. Such a fracture surface is typical of a brittle thermoset [48]. No observable differences in the appearance of the fracture surfaces were detected between the two test temperatures.

The fracture surface of a typical epoxy polymer modified solely with $16 \mathrm{wt} \%$ of CSR nanoparticles and tested at room temperature is given in Fig. 6a. These micrographs show ridges due to crack tilting and river lines being formed during fracture [47]. 
Figure 6 Typical fracture surfaces of the bulk epoxy polymers modified with 16 wt $\%$ of CSR nanoparticles fractured at a $20{ }^{\circ} \mathrm{C}$ and b $-80{ }^{\circ} \mathrm{C}$.
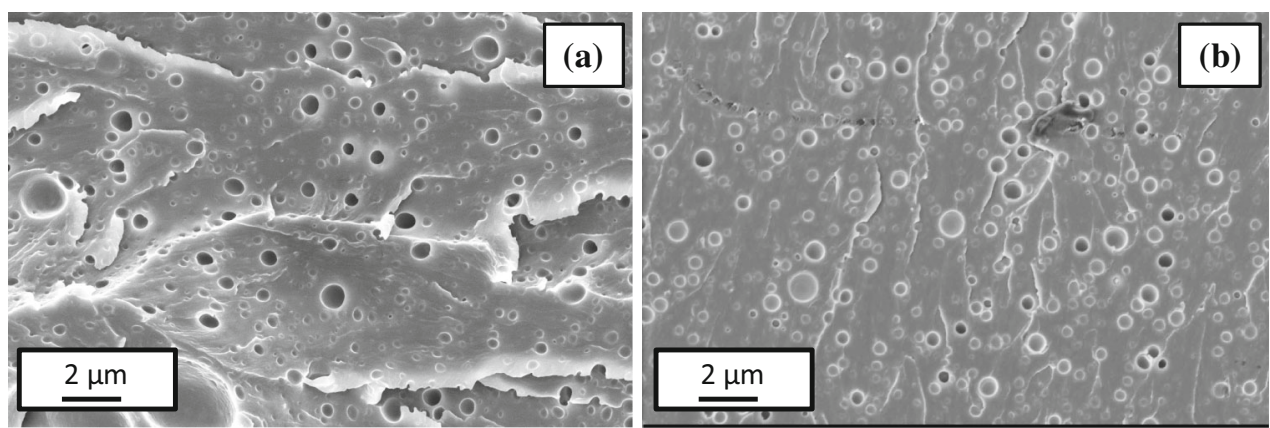

Such features are typical of a mode-I (tensile) fracture. Cavitated CSR nanoparticles are easily identifiable as the circular features in the SEM images of the fracture surfaces and the voids formed from the cavitation process are well-dispersed throughout the material. The mean diameter of the voids is significantly larger than the mean diameter of the CSR particles, indicating that plastic void growth of the epoxy polymer has indeed taken place. An electron micrograph of the fracture surface of the corresponding epoxy polymer containing $16 \mathrm{wt} \%$ of CSR nanoparticles when tested at $-80{ }^{\circ} \mathrm{C}$ is given in Fig. $6 \mathrm{~b}$. There is much similarity between the two fracture surfaces. In both cases, all of the CSR nanoparticles are observed to have cavitated, followed by subsequent plastic void growth of the surrounding epoxy polymer, and this toughening mechanism creates the voids that may be observed. Some subtle differences at $-80{ }^{\circ} \mathrm{C}$, compared with the tests at $20^{\circ} \mathrm{C}$, are that the size and extent of the ridges due to crack tilting observed is much reduced, and the mean void size is actually slightly greater than at $20^{\circ} \mathrm{C}$. However, this is not necessarily indicative of a greater extent of energy plastic dissipation via the plastic void growth toughening mechanism, as the higher yield stress at $-80^{\circ} \mathrm{C}$ naturally leads to a much smaller plastic zone size. The mean diameter of a CSR void was found to be between 5 and $20 \%$ greater at $-80{ }^{\circ} \mathrm{C}$ than at $20{ }^{\circ} \mathrm{C}$.

Typical fracture surfaces of the bulk epoxy polymers modified solely with silica nanoparticles (at 16 wt \%) which were fractured at 20 and $-80{ }^{\circ} \mathrm{C}$ are given in Fig. 7. Again, there is much similarity between the fracture surfaces at the two test temperatures. The fracture surfaces are both brittle in appearance with river lines evident. It should be noted that the fracture surfaces are much rougher than those of the unmodified epoxy polymer, which will also contribute somewhat to the observed increases in toughness for these materials due to the greater area of surface created [32]. The silica nanoparticles are identifiable as the bright spots in each image. No debonding of the silica nanoparticles was observed at either test temperature.

\section{The CFRP composite materials}

The measured values of the mean mode-I initiation, $G_{\text {Ic,init }}(\mathrm{comp})$, and propagation, $G_{\mathrm{Ic}, \text { prop }}(\mathrm{comp})$, interlaminar fracture energies at both test temperatures are given in Table 2. The error bars represent the standard deviation. The benefits of nano-modification of the composite matrices can be clearly observed, as the CFRP composites with the modified
Figure 7 Typical fracture surfaces of the bulk epoxy polymers modified with 16 $\mathrm{wt} \%$ of silica nanoparticles fractured at a $20{ }^{\circ} \mathrm{C}$ and b $-80{ }^{\circ} \mathrm{C}$.
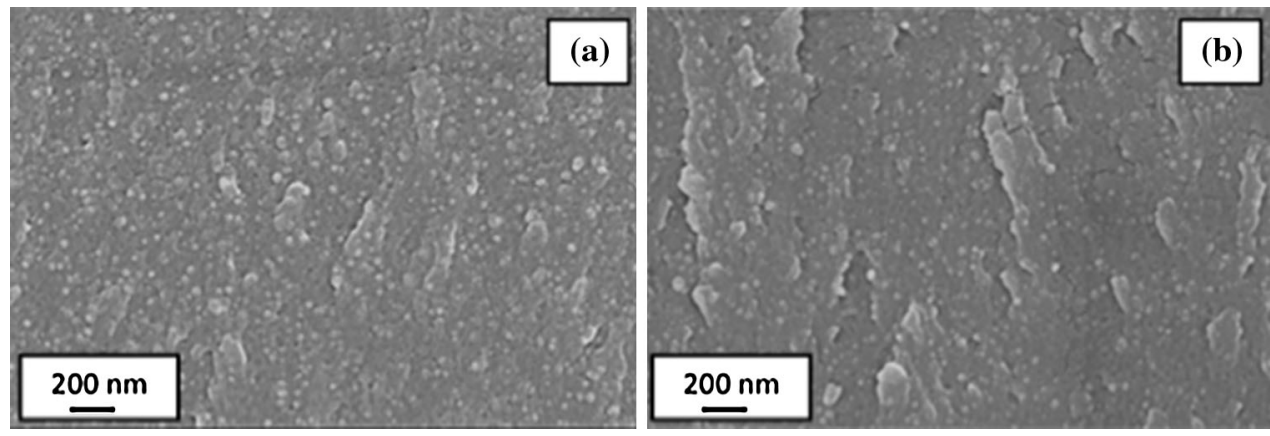
epoxy polymer matrices generally exhibit significantly higher values of both the initiation, $G_{\text {Ic,init }}(-$ comp), and the steady-state propagation, $G_{\text {Ic,prop }}$ (comp), interlaminar fracture energies, although the absolute values of the latter propagation values are dominated by fibre-induced toughening mechanisms, as discussed in detail below.

It is clearly shown in Table 2 that the values of the initiation values of the interlaminar fracture energy for the composites are similar, although not exactly equivalent, to the values of the fracture energy of the bulk epoxy polymers. Thus, the value of the initiation interlaminar fracture energy has virtually no contributions from fibre-induced toughening mechanisms. Now, the propagation interlaminar fracture energy, $G_{\text {Ic,prop }}$ (comp), for a modified composite material is the sum of the contributions from both the toughening effects present in the modified epoxy polymer matrix and the toughening mechanisms associated with the fibres. Assuming that the fibre-induced toughening mechanisms are independent of the type of matrix employed, the measured propagation interlaminar fracture energy of the composite laminates can thus be written as:

$$
\begin{aligned}
& G_{\mathrm{Ic}, \text { prop }}(\operatorname{comp})_{\mathrm{m}}=\left[G_{\mathrm{Ic}, \text { prop }}(\mathrm{comp})-G_{\mathrm{Ic}, \text { init }}(\mathrm{comp})\right]_{\mathrm{u}} \\
& \quad+G_{\mathrm{Ic}, \text { nit }}(\mathrm{comp})_{\mathrm{m}},
\end{aligned}
$$

where the subscripts ' $u$ ' and ' $\mathrm{m}$ ' represent the unmodified and modified composite laminates, respectively. The results calculated via Eq. 7 are given in Table 3 . It is clearly shown that, by comparison with the experimentally measured data in
Table 2, there is a relatively good agreement between the experimental results and the predictions from Eq. 7, especially at $20^{\circ} \mathrm{C}$. These results demonstrate very clearly that the higher values of toughness measured for the composite laminates with nanomodified matrices do indeed come from the nanomodification of the matrix employed.

Figure 8 compares the measured interlaminar fracture energies at -80 and $20^{\circ} \mathrm{C}$. The values for the initiation fracture energies are given in Fig. 8a, while the steady-state propagation energies are given in Fig. $8 \mathrm{~b}$. The trends are broadly similar to those presented for the bulk epoxy polymers in Fig. 5, but the error bars associated with the propagation interlaminar fracture energy measurements are significantly higher than for the fracture energies of the bulk polymers which are presented in Fig. 5. To highlight the main differences between the results shown in Figs. 5, 8a, b, then, firstly, the silica nanoparticles are more effective at toughening the composite laminate at $-80^{\circ} \mathrm{C}$ (i.e. subscript 'LT') than at $20^{\circ} \mathrm{C}$ (i.e. subscript ' $\mathrm{RT}$ '). Secondly, the values of the propagation interlaminar fracture energies in Fig. $8 \mathrm{~b}$ of the composite laminates at $-80{ }^{\circ} \mathrm{C}$ are not statistically dependent upon the type and amount of nanoparticles added to the matrix. Thirdly, while an increase in CSR content, up to $8 \mathrm{wt} \%$, led to an increase in measured fracture energy for the bulk polymers in Fig. 5, the measured initiation fracture energy shown in Fig. 8a does not behave similarly. Regardless, the composites containing 8 wt $\%$ silica nanoparticles perform best at $-80{ }^{\circ} \mathrm{C}$, with a measured initiation

\begin{tabular}{|c|c|c|c|c|c|}
\hline \multirow[t]{2}{*}{ Silica (wt\%) } & \multirow[t]{2}{*}{ CSR (wt\%) } & \multicolumn{2}{|l|}{$20{ }^{\circ} \mathrm{C}$} & \multicolumn{2}{|l|}{$-80{ }^{\circ} \mathrm{C}$} \\
\hline & & Calculated $G_{\text {Ic,prop }}(\operatorname{comp})\left(\mathrm{J} / \mathrm{m}^{2}\right)$ & Difference (\%) & Calculated $G_{\text {Ic,prop }}(\mathrm{comp})\left(\mathrm{J} / \mathrm{m}^{2}\right)$ & Difference $(\%)$ \\
\hline 0 & 0 & - & - & - & - \\
\hline 0 & 4 & $1539 \pm 104$ & +0.1 & $981 \pm 119$ & -17.7 \\
\hline 0 & 8 & $1810 \pm 163$ & +7.7 & $1165 \pm 173$ & +6.4 \\
\hline 0 & 16 & - & - & - & - \\
\hline 4 & 0 & $1246 \pm 98$ & +6.5 & $911 \pm 137$ & -22.9 \\
\hline 8 & 0 & $1274 \pm 119$ & -2.8 & $951 \pm 118$ & -11.29 \\
\hline 16 & 0 & - & - & - & - \\
\hline 4 & 4 & $1437 \pm 151$ & -11.5 & $1018 \pm 215$ & -14.3 \\
\hline 4 & 8 & $1604 \pm 89$ & -13.3 & $1034 \pm 84$ & -12.7 \\
\hline 8 & 4 & $1442 \pm 106$ & -5.3 & $1084 \pm 110$ & -0.6 \\
\hline 8 & 8 & $1617 \pm 130$ & -8.2 & $1279 \pm 118$ & -5.4 \\
\hline
\end{tabular}

Table 3 Calculated propagation fracture energies for the CFRP composites

The ' $\%$ difference' represents the difference between the predictions from Eq. 7 shown in Table 3 and the measured values given in Table 2 

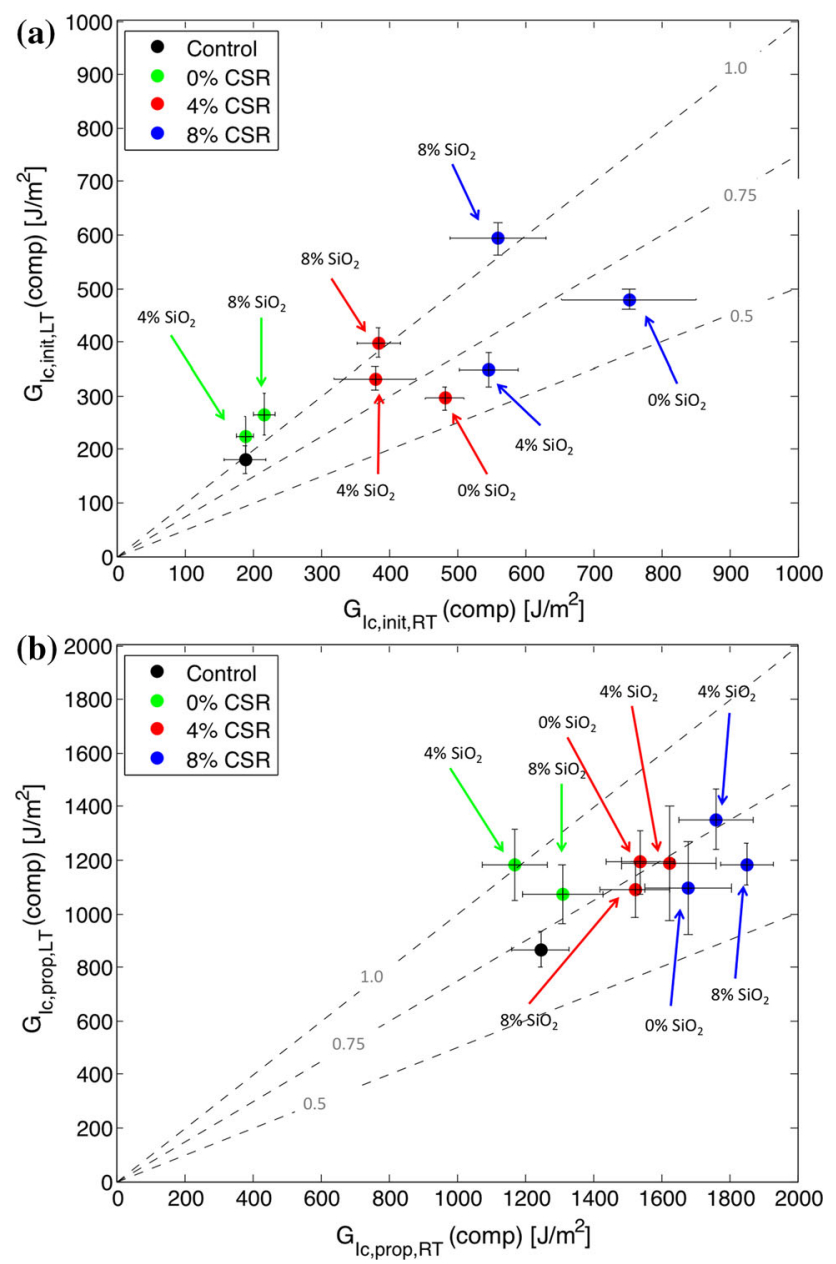

Figure 8 Comparison of the values of the measured a initiation and $\mathbf{b}$ steady-state propagation interlaminar fracture energies of the CFRP composites at 20 and $-80{ }^{\circ} \mathrm{C}$. (The dashed lines have decreasing slopes of $1.0,0.75,0.5$, respectively to aid interpretation of the data.).

fracture toughness greater than that at measured at room $20^{\circ} \mathrm{C}$. Finally, the ratio of the values of toughness, $G_{\text {Ic,prop,LT }}(\mathrm{comp}) / G_{\text {Ic, prop,RT }}$ (comp), for the composites containing the CSR nanoparticles is approximately 0.75 , which is higher than that observed for the bulk epoxy polymers where the ratio was about 0.5. This observation arises from the dominance of the fibre-toughening mechanisms, compared with the toughening mechanisms associated with the nanoparticles in the epoxy polymer matrix.

\section{Fractographic studies: fibre composite materials}

Figure 9 presents micrographs of the fracture surface of the CFRP laminates with an unmodified epoxy matrix fractured at $20{ }^{\circ} \mathrm{C}(\mathrm{a}, \mathrm{b})$ and $-80{ }^{\circ} \mathrm{C}(\mathrm{c}, \mathrm{d})$. Scarping of the interstitial matrix between the fibres is clearly evident at both test temperatures, although it is more pronounced at $20^{\circ} \mathrm{C}$. The fibre-toughening mechanisms can be identified as single-fibre debonding and peeling as well as breaking of large fibre bundles. It should be noted that a mixture of these mechanisms was identified for each test specimen and there appeared to be no clear preference for one fibre-toughening mechanism over another at either test temperature.

Typical micrographs of the fracture surfaces of the CFRP laminates containing a silica-nanoparticlemodified matrix and fractured at room temperature are presented in Fig. 10. It can be observed that there are some notable differences in the fracture surfaces between the addition of $4 \mathrm{wt} \%(\mathrm{a}, \mathrm{b}$ and $\mathrm{c})$ and the addition of $8 \mathrm{wt} \%$ (d, e and $\mathrm{f}$ ). In the case of the composite laminate modified with $4 \mathrm{wt} \%$ of silica nanoparticles, the matrix interstitial to the fibres remains generally well bonded to the fibres (Fig. 10a) and the fibres are observed to peel-off in bundles, see Fig. 10b, c. This is a very effective fibre-related toughening mechanism and indicates that the crack propagation path is switching between plies. However, in the case of the laminate modified with $8 \mathrm{wt} \%$ of silica nanoparticles, there is no evidence of fibrebundle peeling. Instead, individual fibre defibrillation is observed, see Fig. 10d. In both cases the level of fibre-bundle bridging and fibre bridging observed on the fracture surfaces is consistent with the observations of fibre bridging during testing. The extent to which both fibre bridging and fibre-bundle bridging dominates the fracture process can be clearly observed by the side-view photograph of a DCB specimen taken during the test as shown in Fig. 11. Although Fig. 11 presents an extreme case, as it demonstrates fibre-bundle bridging as well as fibre bridging, spanning $8 \mathrm{~mm}$ across the cracked faces, fibre bridging was routinely observed to span $4 \mathrm{~mm}$ across the cracked faces. The fracture surfaces are characterised by the presence of some large matrixrich regions, see Fig. 10e, and there is some evidence of fibre breaking, which again is a very effective fibrerelated toughening mechanism. In both cases, the fibres are relatively clean, indicating that the fibrematrix adhesion is relatively poor.

Figure 12 presents typical fracture surfaces of the CFRP laminates containing $8 \mathrm{wt} \%$ of CSR nanoparticles in the epoxy polymer matrix (see a, b, c) and a 
Figure 9 Fracture surfaces of the CFRP composites employing the unmodified epoxy polymer as the matrix tested at $\mathbf{a}, \mathbf{b} 20^{\circ} \mathrm{C}$ and $\mathbf{c}$, d $-80{ }^{\circ} \mathrm{C}$.
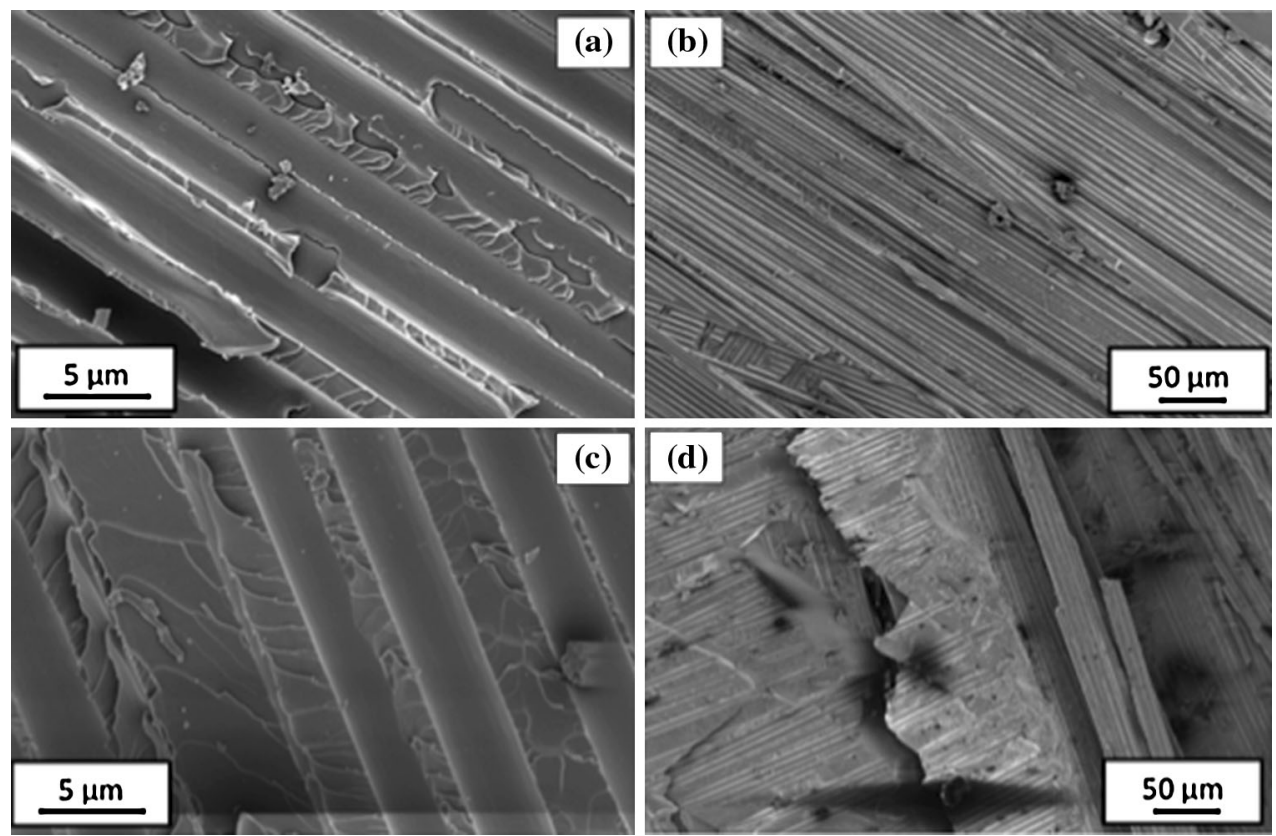

Figure 10 Typical facture surfaces of the CFRP composites fractured at room temperature with an epoxy matrix modified with $\mathbf{a}-\mathbf{c} 4$ $w t \%$ of silica nanoparticles and $\mathbf{d}-\mathbf{f} 8 \mathrm{wt} \%$ of silica nanoparticles.
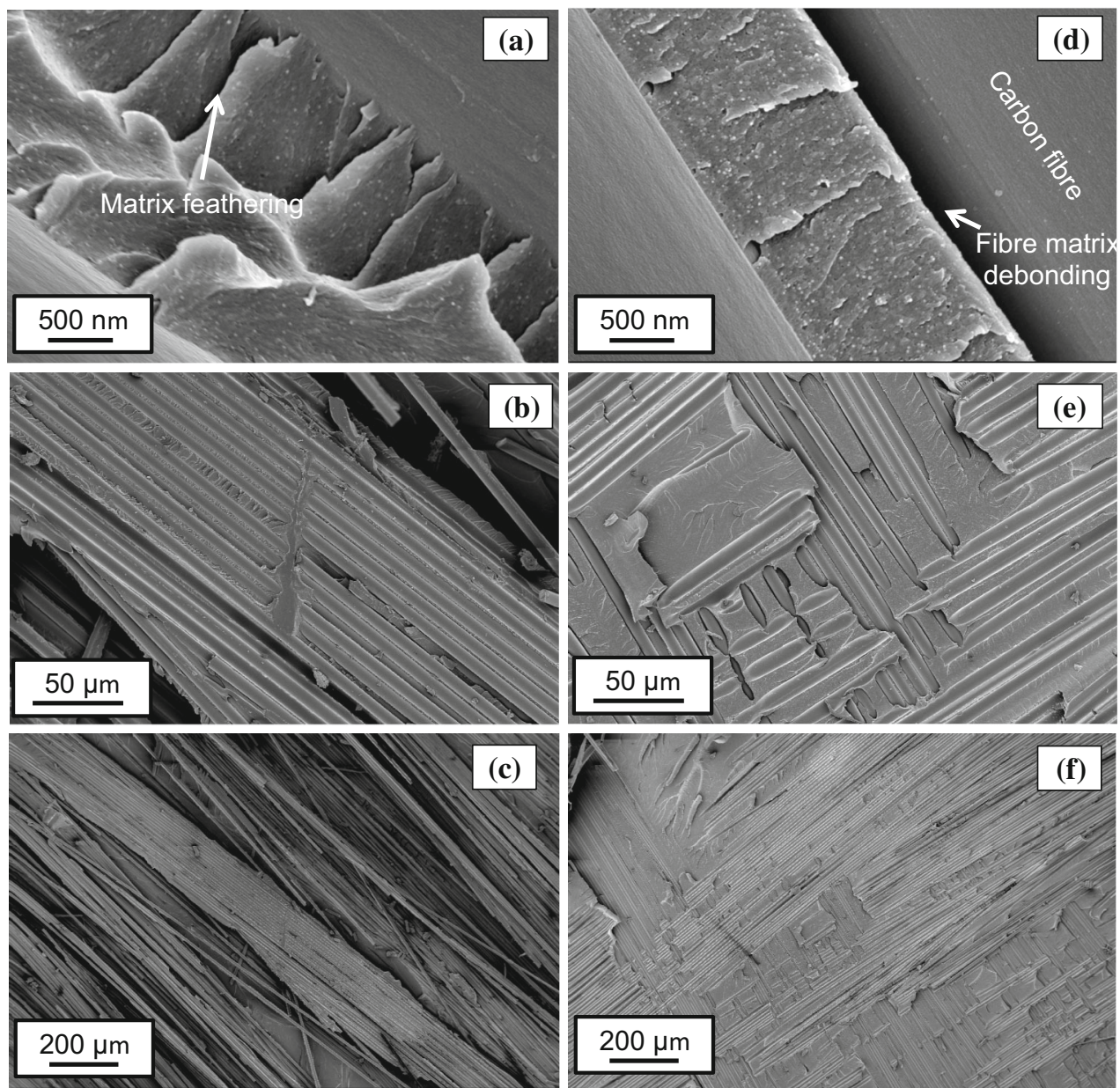


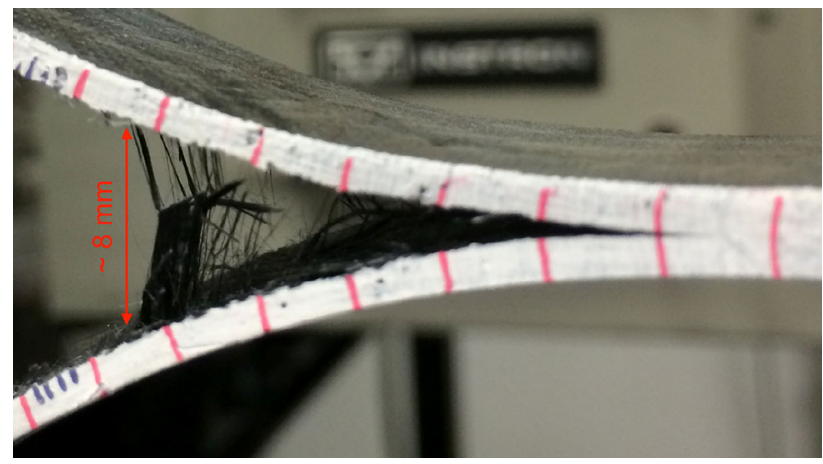

Figure 11 Side-view photograph of DCB test specimen of the CFRP composite with a matrix modified with $4 \mathrm{wt} \%$ silica nanoparticles taken during the interlaminar fracture test. The fibre bridging and fibre-bundle bridging toughening mechanisms are clearly evident.

hybrid-modified epoxy polymer containing $8 \mathrm{wt} \%$ of CSR nanoparticles and $8 \mathrm{wt} \%$ of silica nanoparticles (see $d, e, f$ ). The fracture surfaces are similar to those presented in Figs. 9, 10, and evidence of fibre peeling and fibre fracture can be observed. Cavitation of the rubber nanoparticles is also clearly observed in the matrix between the fibres, see Fig. 12a, d. However, in some cases the distance between the fibres can be very small, see Fig. $12 \mathrm{~d}$, and this will limit the effectiveness of the toughening mechanisms which involve plastic deformation of the epoxy polymer matrix.

\section{Toughening mechanisms}

Huang and Kinloch [21, 22] and later Hsieh et al. [14] have demonstrated that the principal toughening mechanisms in silica-nanoparticle and rubber-particle-modified polymers are (a) localised plastic shearbanding and (b) debonding/cavitation of the particles which enables subsequent plastic void growth of the surrounding epoxy polymer. This model has been demonstrated in a recent paper, via using a Bayesian statistical analysis, to be the most accurate model for predicting the toughness of toughened polymers [49]
Figure 12 Typical facture surfaces of the CFRP composites fractured at room temperature with an epoxy matrix modified with $\mathbf{a}-\mathbf{c} 8$ wt $\%$ of CSR nanoparticles and d-f 'hybrid' of $8 \mathrm{wt} \%$ of silica $+8 w t \%$ of CSR nanoparticles.
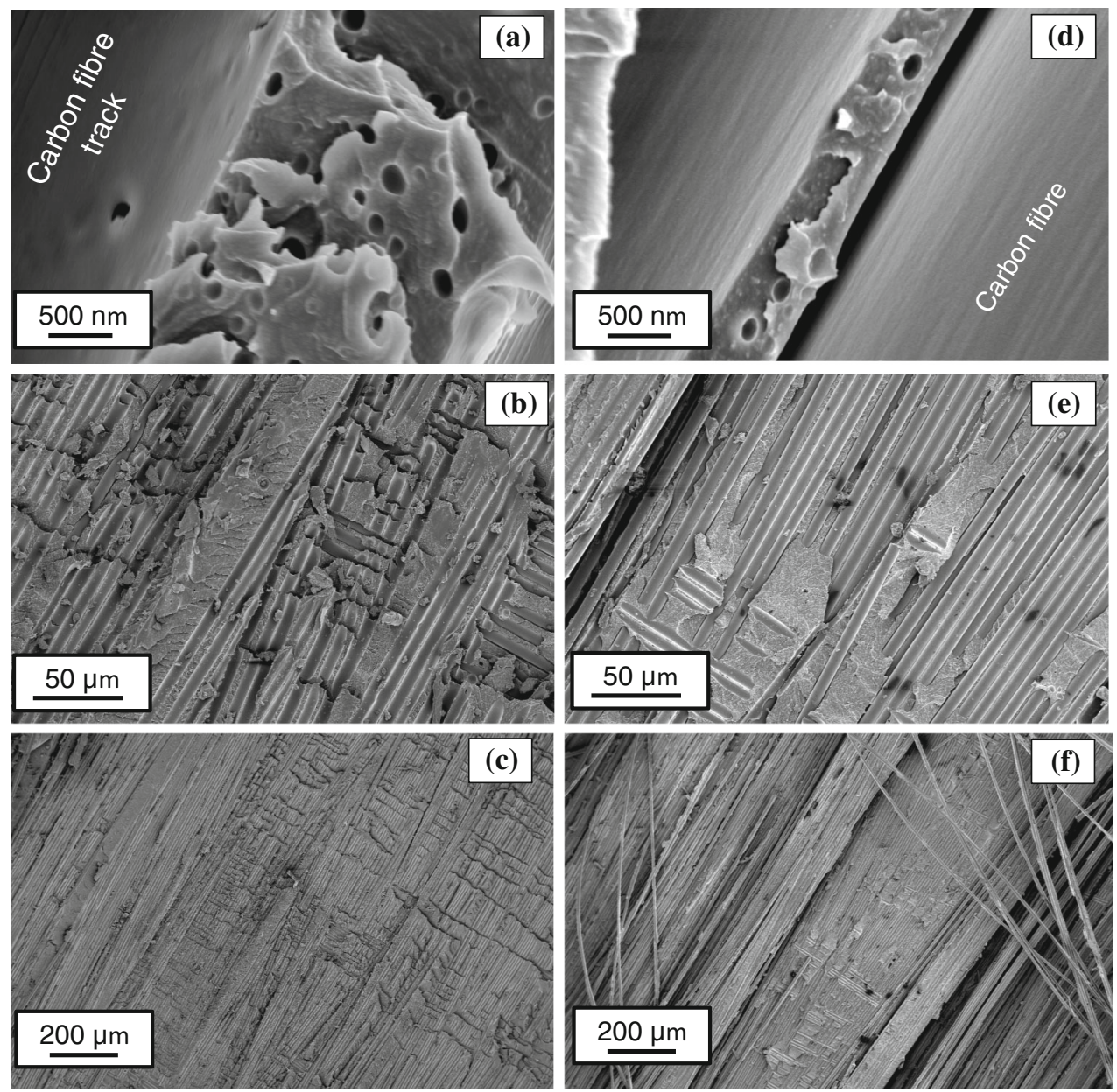
that these workers examined. Thus, the role of the particles is to initiate these two main toughening mechanisms. The fracture energy of such a modified polymer, $G_{\mathrm{IC}}$ (bulk), can be expressed as the sum of the fracture energy of the unmodified polymer, $G_{\mathrm{CU}}$, plus the contributions from the toughening mechanisms, $\psi$ :

$G_{\mathrm{Ic}}($ bulk $)=G_{\mathrm{CU}}+\Psi$,

with:

$\Psi=\Delta G_{\mathrm{s}}+\Delta G_{\mathrm{v}}$,

where the terms on the right-hand side of Eq. 9 represent the fracture energy contributions from localised shear-banding (s) and plastic void growth (v), respectively. (The energy associated with debonding/cavitation of the particles is negligible and can be ignored [18].) The contribution from shear-band yielding between the particles can be expressed as

$\Delta G_{\mathrm{s}}=0.5 V_{\mathrm{p}} \sigma_{\mathrm{yc}} \gamma_{\mathrm{f}} F^{\prime}\left(r_{\mathrm{y}}\right)$,

where $V_{\mathrm{p}}$ is the volume fraction of particles present, $\sigma_{\mathrm{yc}}$ is the compressive yield stress, $\gamma_{\mathrm{f}}$ is the true fracture strain of the unmodified polymer (and both these terms may be determined from the plane-strain compression test), and $F^{\prime}\left(r_{\mathrm{y}}\right)$ is a polynomial function which depends upon the particle radius, $r_{\mathrm{p}}$, the volume fraction of particles, $V_{\mathrm{p}}$, and the plastic zone radius $r_{\mathrm{y}}$, of the modified epoxy polymer [14]. The value of $r_{\mathrm{y}}$ can be calculated from

$r_{\mathrm{y}}=K_{\mathrm{vm}}^{2}\left(1+\frac{\mu_{\mathrm{m}}}{\sqrt{3}}\right)^{2} r_{\mathrm{yu}}$,

where $K_{\mathrm{vm}}$ is the maximum stress concentration factor around the periphery of the particle, or the void (as appropriate), in the polymer as calculated by Huang and Kinloch [22] and Guild and Young [50,51], $\mu_{\mathrm{m}}$ is the pressure-sensitivity coefficient of the polymer and $r_{\mathrm{yu}}$ is the Irwin prediction of the plastic zone size under plane-strain conditions. It is important to note that the stress concentrations around the peripheries of the particles and, or, voids depend upon whether the particle is rigid, i.e. silica nanoparticles, or soft, i.e. CSR nanoparticles and voids. Nevertheless, shear bands between both rigid and soft particles have been observed experimentally [6] and serve to toughen the polymer independently of whether the particles debond or cavitate $[4,5,34,52]$.

The contribution of plastic void growth to the toughening, $\Delta G_{v}$, is given as:
$\Delta G_{\mathrm{v}}=\left(1-\frac{\mu_{\mathrm{m}}}{3}\right)\left(V_{\mathrm{v}}-V_{\mathrm{p}}\right) \sigma_{\mathrm{yc}} r_{\mathrm{ym}} K_{\mathrm{vm}}^{2}$,

where $\left(V_{\mathrm{v}}-V_{\mathrm{p}}\right)$ is the volume fraction of voids observed on the fracture surface minus the volume fraction of particles observed via AFM [36], and all the other terms have been described above. It is also possible to calculate the term $\left(V_{\mathrm{v}}-V_{\mathrm{p}}\right)$ without resorting to tedious measurements from the fracture surface. This approach assumes that the voids grow until the hoop strain in the void reaches the failure strain of the polymer. This approach has been successfully applied previously, providing an upper limit to the toughenability of the epoxy polymer [36], and the hoop strain approach is appropriate to use when high-quality SEM images of the fracture surface are not available. In the current work, the diameters of the voids formed by the CSR particles were measured directly from the SEM micrographs.

All parameters for the model have been measured at both test temperatures, with the exception of the failure strain, $\gamma_{\mathrm{f}}$, at $-80{ }^{\circ} \mathrm{C}$. The values are given in Tables 1 and 2, and are further detailed in [36]. An estimate of $\gamma_{\mathrm{f}}$ at $-80^{\circ} \mathrm{C}$ was made by assuming a similar increase in $\gamma_{\mathrm{f}}$ at $-80{ }^{\circ} \mathrm{C}$ as that observed by Chen et al. [18]. A value of $\gamma_{\mathrm{f}}=1.05$ was used in the model calculations at $-80^{\circ} \mathrm{C}$. This estimate is further supported by the observation that the void growth in the CSR-modified polymers was slightly greater at $-80{ }^{\circ} \mathrm{C}$ than at $20^{\circ} \mathrm{C}$. In the case of polymers modified with silica nanoparticles, no debonding of the nanoparticles was observed from the SEM images, see Fig. $6 a, b$. Therefore, the only contribution to toughening by the silica nanoparticles is that of localised shear-band yielding. In the case of polymers modified with CSR nanoparticles the presence of voids on the fracture surface indicated that plastic void growth had indeed taken place.

Table 4 presents the predicted values of $\Delta G$ at both test temperatures for the bulk epoxy polymers modified with both the silica and CSR nanoparticles, and compares these values with the experimentally measured values of $\Delta G$. It can be seen that the predictions for the bulk epoxy polymers modified with the CSR nanoparticles are in reasonable agreement with the measured values at both test temperatures. Indeed, the modelling results confirm that the toughening mechanisms identified above can indeed account for the significant increases seen in the toughness of the bulk epoxy polymers by the 
Table 4 Fracture energy predictions based on the Huang-Kinloch model and comparison with measured values for the bulk epoxy polymers

\begin{tabular}{|c|c|c|c|c|c|c|}
\hline & & $\mathrm{wt} \%$ & Actual $\Delta G$ & $\Delta G_{\mathrm{s}}$ & $\Delta G_{\mathrm{v}}$ & $\Delta G_{\mathrm{s}}+\Delta G_{v}$ \\
\hline \multirow[t]{6}{*}{ Silica nanoparticles } & \multirow[t]{3}{*}{$20^{\circ} \mathrm{C}$} & 4 & 15 & 53 & - & 53 \\
\hline & & 8 & 27 & 77 & - & 77 \\
\hline & & 16 & 84 & 107 & - & 107 \\
\hline & \multirow[t]{3}{*}{$-80{ }^{\circ} \mathrm{C}$} & 4 & 97 & 33 & - & 33 \\
\hline & & 8 & 110 & 47 & - & 47 \\
\hline & & 16 & 193 & 65 & - & 65 \\
\hline \multirow[t]{6}{*}{ CSR nanoparticles } & \multirow[t]{3}{*}{$20^{\circ} \mathrm{C}$} & 4 & 333 & 120 & 168 & 288 \\
\hline & & 8 & 758 & 186 & 328 & 514 \\
\hline & & 16 & 1064 & 297 & 616 & 913 \\
\hline & \multirow[t]{3}{*}{$-80{ }^{\circ} \mathrm{C}$} & 4 & 180 & 73 & 114 & 187 \\
\hline & & 8 & 298 & 113 & 216 & 329 \\
\hline & & 16 & 320 & 180 & 389 & 569 \\
\hline
\end{tabular}

addition of the CSR nanoparticles. On the other hand, for the epoxy polymers modified with the silica nanoparticles, the model is in relatively poor agreement with the measured values of the toughness increases seen when such silica nanoparticles are present. The model over-predicts the extent of toughening expected at room temperature for the bulk epoxy polymers modified with silica nanoparticles, while a significant under-prediction is observed at $-80{ }^{\circ} \mathrm{C}$.

The toughening contributions from the silica nanoparticles and CSR nanoparticles in the hybrid epoxy polymers can be calculated by considering, in turn, the individual contributions of each mechanism, and expanding Eq. 8, to give:

$\Psi=\left(\Delta G_{\mathrm{s}}^{\text {silica }}+\Delta G_{\mathrm{v}}^{\text {silica }}\right)+\left(\Delta G_{\mathrm{s}}^{\mathrm{CSR}}+\Delta G_{\mathrm{v}}^{\mathrm{CSR}}\right)$,

where the superscripts denote the particle type responsible for the toughening. Clearly such an approach does not appear to account for interactions between the two types of particles and possible synergies. However, the terms in the equation are calculated from experimentally measured data, such as void size, and therefore any interactions between the toughening mechanisms are implicitly contained within those measurements.

Table 5 presents a comparison of the model predictions from the Huang-Kinloch model with the measured experimental data for the hybrid epoxy polymers at both test temperatures. It can be clearly observed that the majority of the toughening of the polymers comes from the presence of the CSR nanoparticles. The model tends to somewhat under predict the toughening at $20{ }^{\circ} \mathrm{C}$, while excellent agreement between the experimental data and the Huang-Kinloch model predictions is observed at $-80{ }^{\circ} \mathrm{C}$.

The Huang-Kinloch model presented in "Compressive properties" section has been recently extended to include the contribution of fibre-based toughening mechanisms for fibre composites [53]. Namely:

$\Psi=\left(\Delta G_{\mathrm{s}}^{\text {silica }}+\Delta G_{\mathrm{v}}^{\text {silica }}\right)+\left(\Delta G_{\mathrm{s}}^{\mathrm{CSR}}+\Delta G_{\mathrm{v}}^{\mathrm{CSR}}\right)+\Delta G_{\mathrm{f}}$,

Table 5 Fracture energy predictions of the hybrid-modified epoxy bulk polymers based on the Huang-Kinloch model and comparison with the measured values

\begin{tabular}{llllllll}
\hline & Silica wt $\%$ & CSR wt $\%$ & Measured $\Delta G$ & $\Delta G_{\mathrm{s}}^{\text {silica }}$ & $\Delta G_{\mathrm{s}}^{\mathrm{CSR}}$ & $\Delta G_{\mathrm{v}}^{\mathrm{CSR}}$ & $\Delta G_{\mathrm{s}}^{\text {silica }}+\Delta G_{\mathrm{s}}^{\mathrm{CSR}}+\Delta G_{\mathrm{v}}^{\mathrm{CSR}}$ \\
\hline $20{ }^{\circ} \mathrm{C}$ & 4 & 4 & 455 & 48 & 126 & 243 & 417 \\
& 8 & 8 & 1044 & 70 & 195 & 607 & 872 \\
& 8 & 4 & 551 & 47 & 125 & 170 & 342 \\
$-80{ }^{\circ} \mathrm{C}$ & 4 & 8 & 883 & 70 & 193 & 407 & 670 \\
& 4 & 4 & 228 & 29 & 77 & 106 & 210 \\
& 8 & 8 & 297 & 42 & 76 & 122 & 240 \\
& 8 & 4 & 414 & 42 & 119 & 323 & 484 \\
\hline
\end{tabular}


where $\Delta G_{f}$ represents the toughening contribution from the fibres arising from fibre pull-out from the matrix, fibre bridging and fibre fracture. Ye and Friedrich [54,55] have provided a simple model to calculate this contribution based on some experimentally measured parameters:

$\Delta G_{\mathrm{f}}=G_{\mathrm{m}}\left(1+\pi r_{\mathrm{f}} \mathrm{l}_{\mathrm{f}}^{\mathrm{p}} n_{\mathrm{f}}^{\mathrm{p}}\right)+1 / 2 \sigma_{\mathrm{tf}} \varepsilon_{\mathrm{ff}} \pi r_{\mathrm{f}}^{2} l_{\mathrm{f}}^{\mathrm{b}} n_{\mathrm{f}}^{\mathrm{b}}$,

where $r_{\mathrm{f}}$ is the radius of the fibres, $l_{\mathrm{f}}^{\mathrm{p}}$ and $n_{\mathrm{f}}^{\mathrm{p}}$ are the mean pull-out length of a fibre and the number of pulled-out fibres per unit area respectively, and $l_{\mathrm{f}}^{\mathrm{b}}$ and $n_{\mathrm{f}}^{\mathrm{b}}$, are the mean fractured length of a fibre and the number of fractured fibres per unit area. The terms $\sigma_{\mathrm{tf}}$ and $\varepsilon_{\mathrm{ff}}$ are the fracture strength and fracture strain of the fibres. The term $G_{\mathrm{m}}$ represents the fracture of the matrix. This, although close to, is not exactly equivalent to the fracture energy of the bulk matrix, $G_{\text {Ic }}$ (bulk), in Eq. 12, but is dependent on the fibre volume fraction and hence the thickness of the matrix layer between adjacent fibres, or plies. The terms $l_{\mathrm{f}}, n_{\mathrm{f}}^{\mathrm{p}}, l_{\mathrm{f}}^{\mathrm{b}}$ and $n_{\mathrm{f}}^{\mathrm{b}}$ are extremely difficult to measure with any degree of accuracy from the fracture surfaces of the failed composite specimens. For example, there is a wide variation in these values at different points of the fracture surface. This gives rise to the relatively large standard deviations associated with the measurement of the fracture energy of the composites. Indeed, Ye and Friedrich [54, 55] gave no indication when first presenting this model that they had actually undertaken these measurements. Rather they discussed how the value of $\Delta G_{\mathrm{f}}$ increased from zero at crack initiation up to a plateau region as the products $l_{\mathrm{f}}^{\mathrm{p}} n_{\mathrm{f}}^{\mathrm{p}}$ and $l_{\mathrm{f}} n_{\mathrm{f}}^{\mathrm{b}}$ attained their equilibrium values, thus providing a physical interpretation of the $R$-curve behaviour.

Now, there are not large observable differences in the appearance of the fibres from the SEM images of the fracture surfaces of the composite laminates, which are presented in Figs. 9, 10 and 12. The difference in length scale between these images should be taken into account when comparing these images. This is due to the order of magnitude difference in the length scales of the silica nanoparticles and the CSR particles. For example, the fibres all appear to be relatively clean, indicating poor adhesion between the carbon fibres and the epoxy polymer matrix. Therefore, the presence of silica nanoparticles and/or CSR nanoparticles should not significantly affect the fibre-related toughening mechanisms (e.g. fibre debonding, fibre pull-out and fibre bridging) and, hence, the value of $\Delta G_{\mathrm{f}}$ in Eq. 15. This observation acts to confirm that the improvements in the value of $G_{\text {Ic,prop }}$ (comp) for the composite laminates with nanomodified matrices detailed in Table 2 are therefore as a result of the improvement in $G_{\mathrm{Ic}}$ (bulk) via the addition of the nanoparticles. This aspect is discussed in more detail below.

\section{Comparison of the toughnesses of the bulk epoxy polymer and the corresponding CFRP composite}

In Fig. 13, the measured fracture energies of the bulk epoxy polymers versus the measured initiation interlaminar fracture energies of the CFRP composites are plotted for both test temperatures. The general excellent 1:1 correlation between the data at $-80{ }^{\circ} \mathrm{C}$ in Fig. $13 \mathrm{~b}$ is striking. In contrast at $20^{\circ} \mathrm{C}$, see Fig. 13a, only for the three modified epoxy polymers with the lowest values of $G_{\mathrm{Ic}, \mathrm{RT}}$ (bulk) is a good 1:1 correlation observed. It is of interest to note that the value of $G_{\text {Ic }}$ (bulk) beyond which the $1: 1$ correlation is not seen is about $500 \mathrm{~J} / \mathrm{m}^{2}$, and this effect is likely to arise from the toughening mechanisms operating at the crack tip in the epoxy polymer matrix (induced by the presence of the nanoparticles) being restricted by the presence of the nearby fibres in the CFRP composites. Up to this point where the fibres would restrict the development of the crack tip plastic zone, it is not surprising to find such a basic linear dependence between $G_{\mathrm{Ic}, \text { init }}(\mathrm{comp})$ and $G_{\mathrm{IC}}$ (bulk) exists, since the toughness at crack initiation in the composite laminates is dependent on the matrix toughness, as no significant fibre-toughening effects have yet had a chance to develop. This effect of the fibres in a composite restricting the development of crack tip plasticity in the matrix between the fibres, and the transition from a 1:1 relationship between $G_{\text {Ic }}\left(\right.$ comp) and $G_{\text {Ic }}$ (bulk) below $500 \mathrm{~J} / \mathrm{m}^{2}$ to a shallower gradient above $500 \mathrm{~J} / \mathrm{m}^{2}$ has been previously reported by Hunston et al. [56] and subsequent work by Bradley [57] amongst others.

In Fig. 14, the measured fracture energies of the bulk epoxy polymers versus the measured propagation interlaminar fracture energies of the CFRP composites are plotted for tests undertaken at both 20 and $-80{ }^{\circ} \mathrm{C}$. Several interesting observations may be made from these results. The first observation is that 

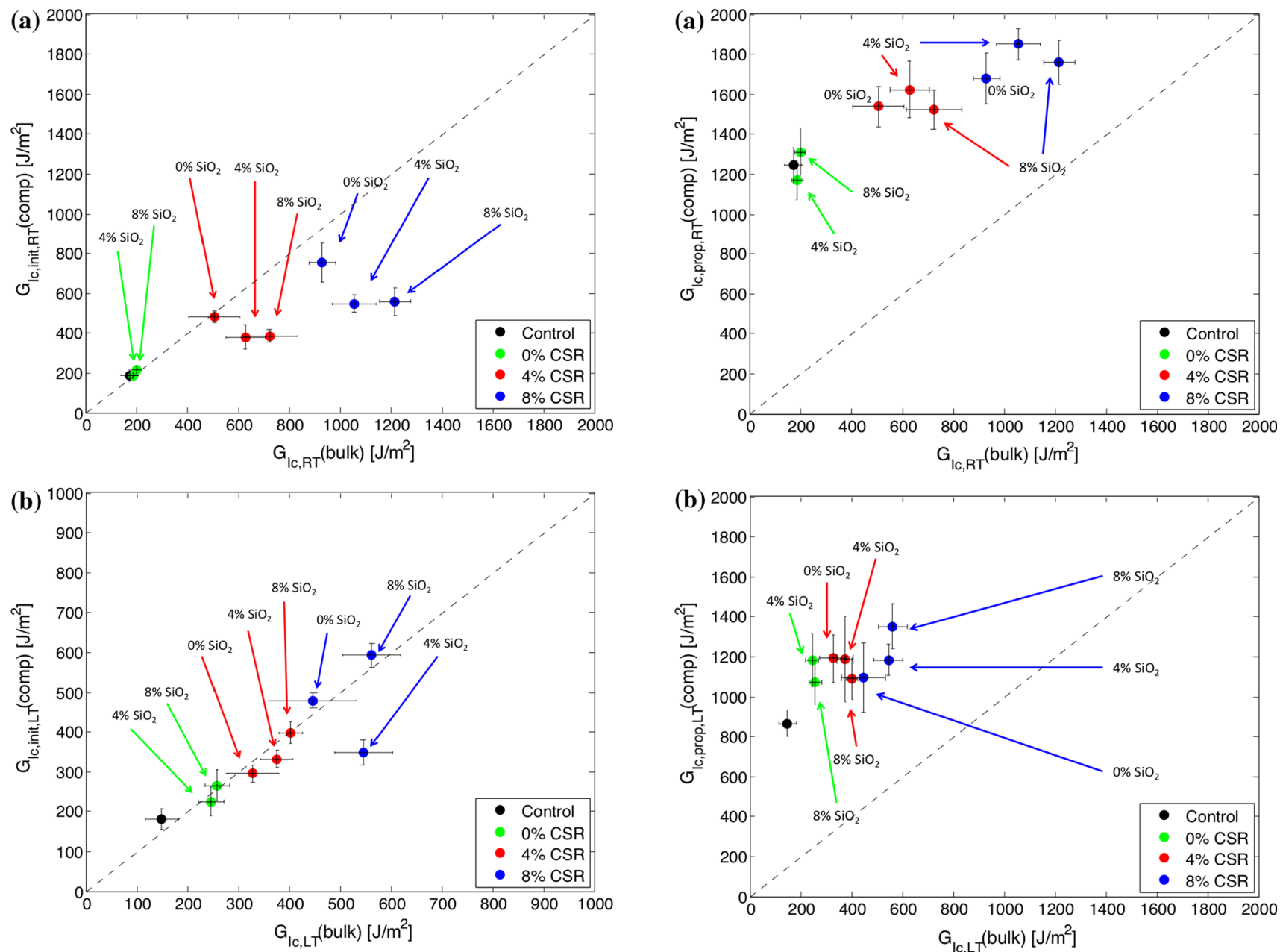

Figure 13 Comparison of the initiation interlaminar fracture energies, as measured by the DCB test, and the bulk epoxy polymer fracture energy, from the SENB tests, at a at $20^{\circ} \mathrm{C}$ and b $-80{ }^{\circ} \mathrm{C}$. (The dashed line on the graph has a slope of $1: 1$ to aid interpretation of the data.).

the steady-state propagation interlaminar fracture energies, $G_{\text {Ic,prop }}$ (comp) of the CFRP composites are far greater in value than the values of toughness, $G_{\mathrm{Ic}}$ (bulk), of the corresponding bulk epoxy polymers at both test temperatures. This arises, of course, from the very significant additional toughening mechanisms of fibre debonding, fibre pull-out and fibre bridging which develop as the interlaminar crack propagates through the CFRP composites. Secondly, these plots show the efficiency of the transferability of toughness between the bulk epoxy polymers and the CFRP composites based on the corresponding epoxy polymer when used as the matrix material. It can be clearly observed that at $20^{\circ} \mathrm{C}$ (see Fig. 14a), in general, any significant increase in the toughness,

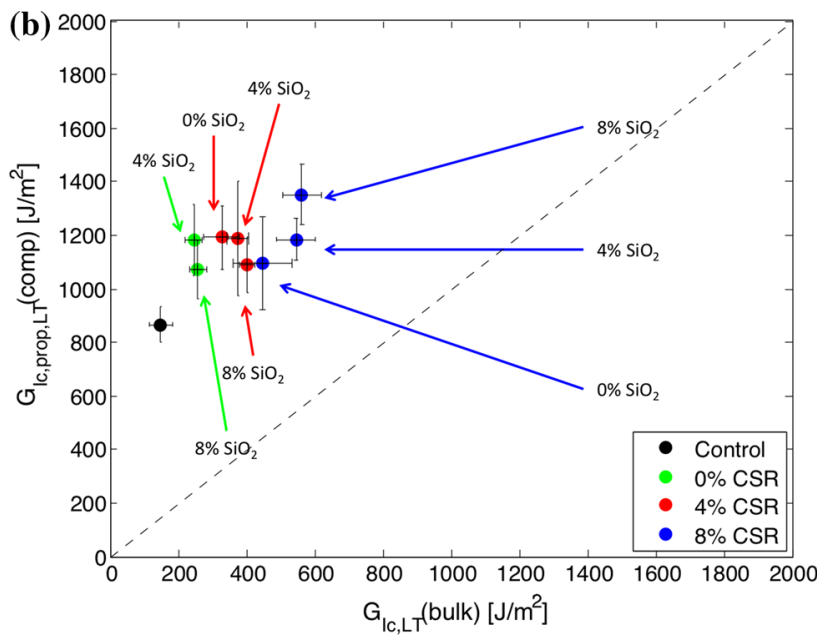

Figure 14 Comparison of the steady-state propagation interlaminar fracture energies, as measured by the DCB test, and the bulk epoxy polymer fracture energy, from the SENB tests, at a at $20{ }^{\circ} \mathrm{C}$ and $\mathbf{b}-80{ }^{\circ} \mathrm{C}$. (The dashed line on the graph has a slope of $1: 1$ to aid interpretation of the data.).

$G_{\mathrm{Ic}, \mathrm{RT}}$ (bulk) of the bulk epoxy polymer due to the addition of CSR and/or silica nanoparticles is transferred directly to the corresponding composite material to give an increase in the interlaminar propagation fracture energy, $G_{\mathrm{Ic}, \mathrm{prop}, \mathrm{RT}}(\mathrm{comp})$, although again a 1:1 transfer is not observed when the value of $G_{\mathrm{Ic}, \mathrm{RT}}$ (bulk) exceeds a value of about $500 \mathrm{~J} / \mathrm{m}^{2}$. Thus, the important role that may be played by modifications to the epoxy polymer matrix in order to increase the toughness of the composites is again very clearly demonstrated by these results. Finally, at $-80{ }^{\circ} \mathrm{C}$, the effectiveness of toughening by the inclusion of silica and/or the CSR nanoparticles in the epoxy is inhibited for both the bulk epoxy polymers and the CFRP composites. However, the decrease in the fracture energies at $-80{ }^{\circ} \mathrm{C}$,

\section{Springer}


compared with $20^{\circ} \mathrm{C}$, was greater for the bulk epoxy polymers than for the corresponding CFRP composites. This arises, of course, due to the fibre-toughening mechanisms being less affected at a test temperature of $-80{ }^{\circ} \mathrm{C}$ than the matrix toughening mechanisms. Since the latter involve plastic deformation mechanisms occurring in the epoxy polymer, which are induced via the presence of the silica nanoparticles and/or CSR nanoparticles, and which are inhibited at this relatively low test temperature, as discussed previously.

\section{Conclusions}

The structure-property relationships of epoxy polymers modified with silica nanoparticles and/or CSR nanoparticles were investigated. The epoxy polymer was crosslinked using an anhydride curing agent and modified with a reactive diluent. Both the bulk epoxy polymers and CFRP composites, based upon these modified epoxy polymers being used as the matrices for such composites, were studied; and two test temperatures of 20 and $-80{ }^{\circ} \mathrm{C}$ were employed. A number of conclusions may be drawn from the results of this work.

- The addition of either CSR nanoparticles or silica nanoparticles to the bulk epoxy polymer leads to significant toughening of the epoxy polymer at both 20 and $-80{ }^{\circ} \mathrm{C}$. The silica nanoparticles are more effective at toughening at $-80{ }^{\circ} \mathrm{C}$ than at $20^{\circ} \mathrm{C}$, while the CSR nanoparticles are less effective at $-80{ }^{\circ} \mathrm{C}$.

- The main toughening mechanisms induced by the presence of the nanoparticles in the bulk epoxy polymers were identified from the present work and from considering the previous literature and involved both localised plastic shear-band yielding initiated by the nanoparticles and plastic void growth around cavitated CSR nanoparticles. An analytical model was applied to predict the toughening contributions and, in general, a reasonable agreement was found between the predicted and measured results, as discussed in detail above.

- The initiation interlaminar fracture energies, $G_{\text {Ic,init }}($ comp), of the CFRP composites could be closely correlated to the bulk fracture energies, $G_{\mathrm{Ic}}$ (bulk), at both test temperatures.
- The steady-state propagation interlaminar fracture energies, $G_{\text {Ic,prop }}$ (comp), of the CFRP composites were far greater in value than the values of the toughness, $G_{\mathrm{Ic}}$ (bulk), of the corresponding bulk epoxy polymers. This arose from the very significant additional fibre-induced toughening mechanisms of fibre debonding, fibre pull-out and fibre bridging that occurred during fracture of the CFRP composites.

- Nevertheless, the use of the epoxy polymers toughened with silica nanoparticles and CSR nanoparticles as the matrices for the CFRP composites was demonstrated to significantly enhance the Mode-I interlaminar fracture toughness of the composites at both test temperatures.

- In general, at $20^{\circ} \mathrm{C}$, any significant increase in the toughness of the bulk epoxy polymer due to the addition of CSR and/or silica nanoparticles was transferred directly to the corresponding composite material to give an increase in both the initiation interlaminar fracture energy and the steady-state propagation fracture energy of the CFRP composite. However, the increase in toughness of the bulk epoxy polymer was not fully transferred to the corresponding CFRP composite once the bulk toughness exceeded a value of about $500 \mathrm{~J} / \mathrm{m}^{2}$.

- At $-80^{\circ} \mathrm{C}$, the values of the interlaminar propagation fracture energies of the composites were increased by the addition of nanoparticles to the epoxy polymer matrix but were statistically independent of the type and amount of nanoparticles added to the matrix.

- Thus, the present experimental and analytical modelling studies have revealed the significant benefits that may be observed from toughening epoxy polymers with silica nanoparticles and CSR nanoparticles, both for use as bulk engineering materials and as the matrices in CFRP composites, at both room temperature and at $-80^{\circ} \mathrm{C}$.

\section{Acknowledgements}

The authors would like to acknowledge the financial support from the Irish Research Council and Marie Curie Actions under the ELEVATE fellowship scheme (Grant No: PD2013/3) for Dr. D. Carolan. Some of the equipment was provided by Dr. A. C. 
Taylor's Royal Society Mercer Junior Award for Innovation.

Open Access This article is distributed under the terms of the Creative Commons Attribution 4.0 International License (http://creativecommons.org/ licenses/by/4.0/), which permits unrestricted use, distribution, and reproduction in any medium, provided you give appropriate credit to the original author(s) and the source, provide a link to the Creative Commons license, and indicate if changes were made.

\section{References}

[1] Kinloch AJ, Young RJ (1983) Fracture behaviour of polymers. Applied Science Publishers, London

[2] Lin M-S, Liu C-C, Lee C-T (1999) Toughened interpenetrating polymer network materials based on unsaturated polyester and epoxy. J Appl Polym Sci 72:585-592

[3] Rowe EH, Siebert AR, Drake RS (1990) Toughening thermosets with liquid butadiene/acrylonitrile polymers. Mod Plast 47:110-117

[4] Kinloch AJ, Shaw SJ, Tod DA, Hunston DL (1983) Deformation and fracture behaviour of a rubber toughened epoxy: 1. Microstructure and fracture studies. Polymer 24:1341-1354

[5] Yee AF, Pearson RA (1986) Toughening mechanisms in elastomer-modified epoxies. Part 1: mechanical studies. J Mater Sci 21:2462-2474. doi:10.1007/BF01114293

[6] Kawaguchi T, Pearson RA (2003) The effect of particlematrix adhesion on the mechanical behavior of glass filled epoxies: part 1. A study on yield behavior and cohesive strength. Polymer 44:4229-4238

[7] Park S-J, Jin F-L, Lee C (2005) Preparation and physical properties of hollow glass microspheres- reinforced epoxy matrix resins. Mater Sci Eng 402:335-340

[8] Johnsen BB, Kinloch AJ, Mohammed RD, Taylor AC, Sprenger S (2007) Toughening mechanisms of nanoparticlemodified epoxy polymers. Polymer 48:530-541

[9] Fine T, Pascault J-P (2006) Structured thermoplastic/thermoset blends using block copolymers. Macromol Symp 245-246:375-385

[10] Hydro RM, Pearson RA (2007) Epoxies toughened with triblock copolymers. J Polym Sci B 45:1470-1481

[11] Chong HM, Taylor AC (2013) The microstructure and fracture performance of styrene-butadiene-methylmethacrylate block copolymer-modified epoxy polymers. J Mater Sci 48:6762-6777. doi:10.1007/s10853-013-7481-8
[12] Ladani RB, Wu S, Kinloch AJ, Ghorbani K, Zhang J, Mouritz AP, Wang CH (2016) Multifunctional properties of epoxy nanocomposites reinforced by aligned nanoscale carbon. Mater Des 94:554-564

[13] Gojny FH, Wichmann MHG, Kopke U, Fiedler B, Schulte K (2004) Carbon nanotube-reinforced epoxy-composites: enhanced stiffness and fracture toughness at low nanotube content. Compos Sci Technol 64:2363-2371

[14] Hsieh TH, Kinloch AJ, Taylor AC, Kinloch IA (2001) The effect of carbon nanotubes on the fracture toughness and fatigue performance of a thermosetting epoxy polymer. J Mater Sci 46:7525-7535. doi:10.1007/s10853-011-5724-0

[15] Bagheri R, Pearson RA (1996) Role of particle cavitation in rubber-toughened epoxies: 1 . Microvoid toughening. Polymer 37:4259-4538

[16] Pearson RA, Yee AF (1991) Influence of particle size and particle size distribution on toughening mechanism in rubber-modified epoxies. J Mater Sci 26:3828-3844. doi:10. 1007/BF01184979

[17] Lu F, Cantwell WJ, Kausch HH (1997) The role of cavitation and debonding in the toughening of core-shell rubber modified epoxy systems. J Mater Sci 32:3055-3059. doi:10. 1023/A:1018626012271

[18] Chen J, Kinloch AJ, Taylor AC, Sprenger S (2013) The mechanical properties and toughening mechanisms of an epoxy polymer modified with polysiloxane-based core-shell particles. Polymer 54:4276-4289

[19] Quan D, Ivankovic A (2015) Effect of core-shell rubber (CSR) nano-particles on mechanical properties and fracture toughness of an epoxy polymer. Polymer 66:16-28

[20] Cooper V, Ivankovic A, Karac A, McAuliffe D, Murphy N (2012) Effects of bond gap thickness on the fracture of nanotoughened epoxy adhesive joints. Polymer 53:5540-5553

[21] Huang Y, Kinloch AJ (1992) Modelling of the toughening mechanisms in rubber-modified epoxy polymers: part I: finite element analysis studies. J Mater Sci 27:2753-2762. doi:10.1007/BF00540702

[22] Huang Y, Kinloch AJ (1992) Modelling of the toughening mechanisms in rubber-modified epoxy polymers: part II: a quantitative description of the microstructure-fracture property relationship. J Mater Sci 27:2763-2769. doi:10.1007/ BF00540703

[23] Kinloch AJ, Mohammed RD, Taylor AC, Eger C, Sprenger S, Egan D (2005) The effect of silica nano particles and rubber particles on the toughness of multiphase thermosetting epoxy polymers. J Mater Sci 40:5083-5086. doi:10. 1007/s10853-005-7261-1

[24] Azimi HR, Pearson RA, Hertzberg RW (1995) Role of crack tip shielding mechanisms in fatigue of hybrid epoxy 
composites containing rubber and solid glass spheres. J Appl Polym Sci 58:449-463

[25] Spanoudakis J, Young RJ (1984) Crack propagation in a glass particle-filled epoxy resin part 1 effect of particle volume fraction and size. J Mater Sci 19:473-486. doi:10. 1007/BF02403234

[26] Spanoudakis J, Young RJ (1984) Crack propagation in a glass particle-filled epoxy resin part 2 effect of particle-matrix adhesion. J Mater Sci 19:487-496. doi:10.1007/ BF00553572

[27] Lee J, Yee AF (2000) Fracture of glass bead/epoxy composites: on micromechanical deformations. Polymer 41:8363-8373

[28] Nakamura Y, Yamaguchi M, Okubo M, Matsumoto T (1992) Effect of particle size on the fracture toughness of epoxy resin filled with spherical silica. Polymer 33:3415-3426

[29] Moloney AC, Kausch HH, Kaiser T, Beer HR (1987) Parameters determining the strength and toughness of particulate filled epoxide resins. J Mater Sci 22:381-393. doi:10.1007/BF01160743

[30] Kwon S-C, Adachi T, Araki W (2008) Temperature dependence of fracture toughness of silica/epoxy composites: related to microstructure of nano- and micro-particles packing. Composites B 39:773-781

[31] Lange FF (1970) The interaction of a crack front with a second-phase dispersion. Philos Mag 22:983-992

[32] Faber KT, Evans AG (1983) Crack deflection processes-I. Theory. Acta Metall 31:565-576

[33] Faber KT, Evans AG (1983) Crack deflection processes-II. Experiment. Acta Metall 31:577-584

[34] Liang YL, Pearson RA (2009) Toughening mechanisms in epoxy-silica nanocomposites (ESNs). Polymer 50:4895-4905

[35] Hsieh TH, Kinloch AJ, Masania K, Lee JS, Taylor AC, Sprenger S (2010) The toughness of epoxy polymers and fibre composites modified with rubber microparticles and silica nanoparticles. J Mater Sci 45:1193-1210. doi:10.1007/ s10853-009-4064-9

[36] Carolan D, Kinloch AJ, Ivankovic A, Sprenger S, Taylor AC (2016) Toughening of epoxy-based hybrid nanocomposites. Polymer 97:179-190

[37] ISO-527-1 (1996) Plastics - determination of tensile properties - part 1: test conditions for moulding and extrusion plastics. International Organization for Standardization, Geneva

[38] Williams JG, Ford HR (1964) Stress-strain relationships for some unreinforced plastics. J Mech Eng Sci 6:405-417

[39] ISO-13586 (2000) Plastics - determination of fracture toughness $\left(\mathrm{G}_{\mathrm{IC}}\right.$ and $\left.\mathrm{K}_{\mathrm{IC}}\right)$ - Linear elastic fracture mechanics (LEFM) approach. International Organization for Standardization, Geneva
[40] ISO-15024 (2001) Fibre-reinforced plastic compositesDetermination of mode I interlaminar fracture toughness, $\mathrm{G}_{\mathrm{IC}}$, for unidirectionally reinforced materials. International Organization for Standardization, Geneva

[41] Zhang H, Zhang Z, Friedrich K, Eger C (2006) Property improvements of in situ epoxy nanocomposites with reduced interparticle distance at high nanosilica content. Acta Mater 54:1833-1842

[42] Fu S-Y, Feng X-Q, Lauke B, Mai Y-M (2008) Effects of particle size, particle/matrix interface adhesion and particle loading on mechanical properties of particulate-polymer composites. Composites B 39:933-961

[43] Turcsanyi B, Pukanszky B, Tudos F (1988) Composition dependence of tensile yield stress in filled polymers. J Mater Sci Lett 7:160-162

[44] Pukanszky B, Turcsanyi B, Tudos F (1988) Effect of interfacial interaction on the tensile yield stress of polymer composites. In: Ishida $\mathrm{H}$ (ed) Interfaces in polymer, ceramic and metal matrix composites. Elsevier, Amsterdam, pp 467-477

[45] Rey T, Chagnon G, Le Cam J-B, Favier D (2013) Influence of the temperature on the mechanical behaviour of filled and unfilled silicone rubbers. Polym Test 32:492-501

[46] Guild FJ, Kinloch AJ, Taylor AC (2010) Particle cavitation in rubber toughened epoxies: the role of particle size. J Mater Sci 45:3882-3894. doi:10.1007/s10853-010-4447-y

[47] Hull D (1999) Fractography: observing measuring and interpreting fracture surface topography. Cambridge University Press, Cambridge

[48] Andrews EH (1968) Fracture in polymers. Oliver \& Boyd, Edinburgh

[49] Hamdia KM, Zhuang X, He P, Rabczuk T (2016) Fracture toughness of polymeric nanocomposites: evaluation of models performance using Bayesian method. Compos Sci Technol 126:122-129

[50] Guild FJ, Young RJ (1989) A predictive model for particulate-filled composite materials. Part 1. Hard particles. J Mater Sci 24:298-306. doi:10.1007/BF00660971

[51] Guild FJ, Young RJ (1989) A predictive model for particulate-filled composite materials. Part 2. Soft particles. J Mater Sci 24:2454-2460. doi:10.1007/BF01174511

[52] Lee J, Yee AF (2001) Inorganic particle toughening I: micromechanical deformations in the fracture of glass bead filled epoxies. Polymer 42:577-588

[53] Kinloch AJ, Taylor AC, Techapaitoon M, Teo WS, Sprenger $S$ (2016) From matrix nano-phase and micro-phase tougheners to composite macro-properties. Philos Trans R Soc A 374:20150275. doi:10.1098/rsta.2015.0275

[54] Ye L, Friedrich K (1993) Mode I interlaminar fracture of comingled yarn based glass/polypropylene composites. Compos Sci Technol 46:187-198 
[55] Ye L, Friedrich K (1992) Fibre bridging in double cantilever beam specimens and its effect on mode I interlaminar fracture toughness. J Mater Sci Lett 11:1537-1539

[56] Hunston DL, Moulton RJ, Johnston NJ, Bascom WD (1987) Matrix resin effects in composite delamination: mode I fracture aspects. ASTM STP 937:74-94
[57] Bradley WL (1991) Understanding the translation of neat resin toughness into delamination toughness in composites. Key Eng Mater 37:161-198 